\title{
Study of The Biomass, Sand, and Biochar Fluidization in A Typical Bed of Fast Pyrolysis
}

\section{David Vasconcelos}

Universidade Federal da Bahia

José Ferreira Júnior

Universidade Federal da Bahia

George Simonelli

Universidade Federal da Bahia

Luiz Carlos Santos

Universidade Federal da Bahia

Carlos Augusto de Moraes Pires ( $\nabla$ cap@ufba.br)

UFBA: Universidade Federal da Bahia https://orcid.org/0000-0003-4231-6495

\section{Research Article}

Keywords: biomass, sisal residue, biochar, fluidized bed, ternary mixture

Posted Date: February 12th, 2021

DOI: https://doi.org/10.21203/rs.3.rs-184487/v1

License: (c) (i) This work is licensed under a Creative Commons Attribution 4.0 International License. Read Full License 


\section{Study of the biomass, sand, and biochar fluidization in a typical bed of fast pyrolysis}

Vasconcelos, Davida, José M. Ferreira Júnior, José Mário a, Simoneli, George ${ }^{a}$, Luiz Carlos L. dos Santos ${ }^{\mathrm{a}}$, Carlos Augusto M. Pires ${ }^{\mathrm{a}}$

${ }^{a}$ Chemical Reaction Engineering Laboratory, Federal University of Bahia - UFBA, zip code: 40.210-910, Salvador, BA, Brazil

Corresponding author: Dr. Carlos Augusto M. Pires - cap@ufba.br

Abstract: Biomass pyrolysis usually occurs in a fluidized bed reactor formed by sand, biomass, and biochar. Dynamics this fluidization differs from that of literature because the biomass is converted continually in biochar. In this study, a series of experiments have been carried out for ternary mixtures of sand, sisal residue, and biochar, varying the compositions and particle size. The tests were based on two simplification hypotheses (steady state and room temperature) due to fast biomass transformation in bed and low Van der Waals force to large particles. The dynamic characteristics determined included the bed pressure drop and bed fluctuation. The single and combined effects of particle size and composition on the final fluidization velocity $\left(\mathrm{U}_{\mathrm{ff}}\right)$ and particle segregation $(\mathrm{S})$ have been analyzed using response surface (RSM). The Uff and S minimum values were found when the variables were in the smallest particle size and composition levels. New correlations were developed for predicting the values of $U_{\text {ff. }}$ The error from measured values when using the new correlation was $7.6 \%$, while the literature equation was $9.7 \%$. The present correlations predicted reasonably well predicted the $\mathrm{U}_{\mathrm{ff}}$ of ternary mixtures in the fast pyrolysis bed.

Keyword: biomass, sisal residue, biochar, fluidized bed, ternary mixture.

\section{Introdução}

The fluidized bed reactor is one of the most common and commercialized pyrolizers for bio-oil production [1]. This reactor has a bed typically composed of silica sand, which is fluidized by an inert gas. The biomass is injected throughout pyrolysis, remaining in the bed before being transformed into biochar, dragging it from the reactor by an inert gas. Therefore, silica sand, biomass, and biochar must coexist in the bed during the reaction, forming a ternary mixture. 
The maximum biomass conversion into bio-oil and the development of a pyrolysis project are only possible with information about mixing, particle segregation, and the dynamic bed properties. Disregarding such information can result in incomplete transformations of the biomass due to the bed expansion [2], the inefficiency of the heat transfer rate, and low chemical conversion rate in the system [3].

Few researchers have studied the mixtures fluidization with more than two components, most of which cannot be converted into bio-oil, such as dolomite, glass spheres, polyethylene particles, and ilmenite bed [3-6]. As far as we know, only Shao et al. [7, 8] studied the ternary mixtures fluidization of sand and biomass, however, in a square bed.

Despite Shao et al. [7, 8] have evaluated the fluidization pattern and various effects on the fluidization velocity in rectangular beds, these results must not be associated with a cylindrical bed because the fluidization dynamics are different [2]. Then, because of the scarcity of fluidization results in ternary cylindrical beds with biomass, the study of other ternary mixtures' dynamics may be relevant to help understand the phenomena involved in bio-oil production beds.

Jena et al. [4] studied the fluidization of three dolomite samples of different sizes and the same density. These authors found that the average diameter and mass fractions of particles and the gas flow rates considerably affected the bed pressure drop and the beginning of fluidization. The authors found that the minimum fluidization velocity decreasing with the fraction of fines increasing, which is an opposite result to what has been reported by Shao et al. [7]. Jena et al. [4] have also concluded that the calculated minimum fluidization velocity from the Wen and Yu equation had better accuracy than the equations of Chiba et al., Bilbao et al., and Kozney - Carman. On the other hand, they found that the best prediction for the minimum fluidization velocity was given by the equations of Chiba et al. and Kozney - Carman for a mixture with a higher percentage of fine. Asif [9] calculated the minimum fluidization velocity for multicomponent systems from the relationship among the mass fractions and each component's minimum fluidization velocity. He used the data from Jena et al. [4] and found minor errors (1.8 to 5.8\%). Feng et al. [5] studied ternary fluidization with polystyrene particles to evaluate the effect of particle size and pressure distribution on the minimum fluidization velocity. In all tests, the minimum fluidization velocity decreased with the operating pressure increasing. These authors used the equations of Otero and Corella, Obata et al., and Rowe and Nienow to predict the minimum fluidization velocity, obtaining average relative errors of $13.71 \%, 15.02 \%$, and $5.41 \%$, respectively. 
The temperature also influenced the fluidization of inorganic particles [10, 11]. A temperature increase lowers gas density and raises its viscosity, decreasing the minimum fluidization velocity due to the drag force's increase. However, Formizani et al. [10] found minimum fluidization velocity approximately constant when the bed temperature increased for sand particles larger than $800 \mu \mathrm{m}$. According to the authors, this behavior must be related to the decrease in Van der Waals forces' importance between large adjacent particles.

Previous studies on the ternary mixture fluidization show that there is little information available in the literature, mainly regarding the behavior of cylindrical beds with biomass. Thus, the present work aims to study the fluidization characteristics of a ternary mixture of sand, sisal residue, and biochar by statistical analysis in a lab-scale cylindrical fluidized bed. Consequently, a more significant understanding of the dynamics of segregation of mixtures was clarified. Besides, this work presented a correlation for the determination of fluidization velocity by dimensional analysis.

\section{Materials and methods}

\subsection{Initial consideration}

The study of fluidization during the continuous pyrolysis process at $450-550{ }^{\circ} \mathrm{C}$ is difficult due to the biomass and biochar flow during the biomass transformation by the temperature (Fig. 1 (a)). Two simplifying hypotheses were assumed to overcome these difficulties: (a) batch fluidization; (b) fluidization at room temperature. The first hypothesis is based on the biomass transformation's fastness into biochar [12], which allowed us to adopt particles with constant masses in each teste.

Fig. 1 Fluidization of sand, biomass, and biochar: (a) in a continuous system (with reaction); (b) in a batch system (without reaction)

The second hypothesis disregards the influence of temperature on the bed fluidization due to the large size of the sand particles and the more significant proportion of this material. This simplification is based on Formisani et al. [10], who found constants values for the minimum fluidization velocities of sand at bed temperatures above $800{ }^{\circ} \mathrm{C}$ when the particle size range was $800-1000 \mu \mathrm{m}$. However, as the particle size used in this study varied between 550-1090 $\mu \mathrm{m}$, we probably found slightly higher fluidization velocity for particles below $800 \mu \mathrm{m}$, since the tests were carried out at room temperature.

\subsection{Sisal residue, biochar, and sand}


The biomass chosen for this work was the sisal residue, whose particle geometry varies between flat, elongated, and cells. The sisal residue was obtained after processing to obtain sisal fibers and is therefore considered a primary by-product of the sisal fiber production process. This biomass and its biochar were obtained in a fast pyrolysis pilot plant for bio-oil production, with a bubbling fluidized bed reactor [13].

The particles of dry sisal residue and biochar were characterized by sieving, using the ISO 565 scale [14]. The particle size distribution was determined using sieve openings of $1 / 4-3 / 8$ in and 12 to $31 / 2$ mesh. The average particle length was determined by the sieve openings' average size that retained the material and the size immediately preceding it. The average particle size of biochar was kept constant in all tests at 0.78 $\mathrm{mm}\left(\mathrm{d}_{\mathrm{bchar}}\right)$. This particle size was chosen because it represents more than $90 \%$ of biochar that leaves in the pilot reactor. Silica sand was selected because it is an essential fluidizing material due to its excellent ability to stabilize the bed thermally. The properties of these particles were given in Table 1.

Table 1 Materials properties

\subsection{Experimental setup}

The experimental setup is illustrated in Fig. 2. The column was made of transparent acrylic, with an internal diameter of $53 \mathrm{~mm}$ and a height of $485 \mathrm{~mm}$. The distributor was a stainless-steel perforated plate with 0.04 mm diameter openings, and the fluidized bed was operated with dry air supplied to the bottom. The air's volumetric flow rate was measured by rotameter, with graduations from 11.67 to $116.67 \mathrm{~L} / \mathrm{min}$, and controlled by a regulating valve. Two pressure taps, located just above the distributor level and at the top of the column, were connected in a U-manometer to measuring the total pressure drop across the bed during fluidization experiments. A graduated scale is used for reading the drop pressure with a $0.5 \mathrm{~mm}$ approximation, which gives rise to an uncertainty never exceeding $1 \%$.

Fig. 2 Fluidization system

\subsection{Fluidization velocity}

The minimum fluidization velocity is one of the most used parameters to characterize the beginning of a well-mixed ternary system $[7,8]$. However, this parameter has no practical application in many multicomponent systems, especially when the particles' size or density is not constant [6]. The particles can 
then undergo segregation at different levels and create a transition region between the fixed and the bubbling bed. In this scenario, some researchers agree that the mixture is well fluidized from the final fluidization velocity $[15,16]$.

All tests in this study were conducted using a homogeneous mixture of sand, sisal residue, and biochar. A mobile fluidization front was established at the top of the bed, with a gradual increase in the gas flow rate. At this point, when pressure drop $(\Delta \mathrm{P})$ deviates for the first time from the fixed bed, the initial fluidization velocity is observed $\left(\mathrm{U}_{\mathrm{if}}\right)$. As the gas flow rate increases, this front moves in the bed and goes down to the column's bottom. The fluidization process in this mixture was accompanied by segregation until a new velocity threshold, at which point the bed is in a fully fluidized state. When the final value of $\Delta \mathrm{p}$ is reached, the final fluidization velocity is observed $\left(\mathrm{U}_{\mathrm{ff}}\right)$.

Defluidization profiles were used to illustrate fluidization cases in which segregation interfered with the system's mixing. In these profiles, it was possible to observe that the pressure drops initially remained constant, configuring a horizontal line in the graph of pressure drop versus gas velocity. At a given gas velocity, it was observed that the pressure drop starts to decrease, thus starting the segregation process $\left(\mathrm{U}_{\mathrm{is}}\right)$.

By gradually decreasing the gas flow rate, the fixed bed condition is achieved when the pressure drop variation remains constant until the bed becomes completely static. The fixed bed velocity $\left(\mathrm{U}_{\mathrm{fb}}\right)$ is the point that represents the beginning of constant variation of pressure drop.

\subsection{Evaluation method}

The influence of the particle size of the sand $\left(\mathrm{d}_{\text {sand }}\right)$ and sisal residue $\left(\mathrm{d}_{\mathrm{bio}}\right)$, as well as the mass fraction of sisal residue ( $\mathrm{w}_{\mathrm{bio}}$ ) and biochar ( $\mathrm{w}_{\mathrm{bchar}}$ ), on the average percentage of segregation $(\mathrm{S})$ and final fluidization velocity $\left(\mathrm{U}_{\mathrm{ff}}\right)$, were studied using the design of experiments approach. In this study, the tests were based on a central composite design, useful in the response surface methodology (RSM), for the construction of a second-order (quadratic) model for the response variable [17].

Table 2 shows the tests related to the complete factorial design, which refers to all possible combinations of the independent variables, the replicates at the central point to determine the experimental error, and the choice of the test of statistical significance. Besides, it shows axial points since the behavior of the variables was expected to be nonlinear. The values of the independent variables $\left(\mathrm{d}_{\text {sand }}, \mathrm{d}_{\mathrm{bio}}, \mathrm{w}_{\mathrm{bio}}, \mathrm{w}_{\mathrm{bchar}}\right)$ used in the tests were coded in $-1,0$ and +1 , to represent the lowest, intermediate, and highest values, respectively. The intermediate values of the variables were called central points $(0)$. The axial points were calculated from 
the coded values -2 and +2 , representing the distance between the central point and the axial point for the four independent variables [17].

Table 2 Experimental design with output response variables based on the central composite rotatable design The average segregation (S) percentage was found from the defluidization curve, within the limits of the initial segregation velocity $\left(\mathrm{U}_{\mathrm{is}}\right)$ and the fixed bed velocity $\left(\mathrm{U}_{\mathrm{fb}}\right)$ (Fig. 3).

Fig. 3 Fluidization with segregation

From Fig. 3, S was calculated from the sum of the spacing between the superficial gas velocity of the gas in the real bed ( $\mathrm{Vi}$ ) and the corresponding hypothetical value to the fixed bed ( $\left.\mathrm{Vi}^{\prime}\right)$ divided by the number of tests (n) in the evaluated velocity range (Eq. 1).

$S=\frac{\sum_{i=1}^{n} 100\left(\frac{V_{i^{-}} V_{i^{\prime}}}{V_{i^{\prime}}}\right)}{n}$

The relationship between the dependent variable $\mathrm{S}$ (ou $\mathrm{U}_{\mathrm{ff}}$ ) is complex, and the interaction effects must be teased out using statistical analysis [18, 19]. The response surface methodology (RSM) consists of graphically representing each parameter's influence and their interactions in the results, which can be used to derive the ideal conditions to improve the process [18]. To compare the different measures, we used the analysis of variance (ANOVA) [18]. ANOVA is the statistical treatment commonly applied to the experimental results to test the variables' significance and their interactions through their P-values. The experimental fluidization of multicomponent systems is complicated due to fluctuations in the pressure drop caused by the material segregation [20]. For this reason, the statistical significances were $90 \%$ and $80 \%$ to $\mathrm{S}$ and $\mathrm{U}_{\mathrm{ff}}$, respectively. Consequently, P-values less than $0.1(\mathrm{~S})$ or $0.2\left(\mathrm{U}_{\mathrm{ff}}\right)$ indicate that the studied variables were significant and could be part of the model.

\subsection{Previous modeling for minimum fluidization velocity}

Many correlations for the minimum fluidization velocity $\left(\mathrm{U}_{\mathrm{mf}}\right)$ of the binary mixture have been developed in recent years. However, relatively few researchers have investigated correlations for ternary mixtures [4, $5,7,9]$. In many of these studies, the calculation of the $U_{\mathrm{mf}}$ depends on the $\mathrm{U}_{\mathrm{mf}}$ of the pure component. Thus, it is challenging to use correlation to make $U_{m f}$ predictions for systems with biomass due to the difficulties of fluidizer the beds containing only this type of particle. Nevertheless, Shao et al. [7] developed 
an excellent correlation for systems with biomass. They have adapted the correlations for binary systems proposed by Coltters and Rivas [21] and Zhong et al. [22] and found a correlation for ternary systems of sand and two biomass particles (Eq. 2-6).

$U_{m f}=C 1\left[\frac{d_{p e}^{2}\left(\rho_{p e}-\rho_{g}\right) g}{\mu_{g}}\left(\frac{\rho_{p e}}{\rho_{g}}\right)^{C 2}\right]^{C 3}$

Where $\rho_{p e}$ is the effective particle density of the particle mixture, and $d_{p e}$ is the effective diameter of particle mixture; $\rho_{g}$ is the density of the fluidized gas; $\mu_{g}$ is the gas viscosity; $\mathrm{C} 1=1.28 \times 10^{-3} ; \mathrm{C} 2=1.2 \mathrm{e}$ $\mathrm{C} 3=0.356$.

$\rho_{p e}=x_{1} \rho_{p e 1}+x_{2} \rho_{p 2}$

Eq. (3) was used to calculate the effective particle density of the particle mixture; where $x_{1}$ is the mass fraction of irregular particles in the mixture and $x_{2}$ is the mass fraction of bed material in the mixture, with $x_{2}>x_{1} ; \rho_{p e 1}$ e $\rho_{p 2}$ are the effective particle density and the bed material density, respectively.

$d_{p e}=d_{p 2}\left[\left(\frac{\rho_{p 2}}{\rho_{p e 1}}\right)\left(\frac{d_{p e 1}}{d_{p 2}}\right)\right]^{x_{1} / x_{2}}$

$\rho_{p e 1}=\sum \alpha_{i} \rho_{p i}$

$d_{p e 1}=\sum \alpha_{i} d_{p i}$

Eq. (4) was used to calculate the effective diameter of particle mixture, where $d_{p e 1}$ e $d_{p 2}$ is the effective particle diameter of the irregular particles and diameter of the bed material, respectively. Eqs. (5) and (6) were used to calculate the density and the irregular particles' diameter, respectively; where $\alpha_{i}, \rho_{p i}$ e $d_{p i}$ represents the volume fraction, particle density, and effective diameter of the individual type of irregular particle within the mixture, respectively.

The work of Shao et al. [7] concluded that Eq. (2) could satisfactorily predict the $U_{\mathrm{mf}}$ values for a system with any number of components with an average relative error of prediction of $11.7 \%$.

\subsection{Novel model}

In this article, correlations capable of predicting the ternary mixture's final fluidization velocity were developed based on dimensional analysis. The factors that should influence the final fluidization velocity of the mixture of sand, sisal residue and biochar are written as Eq. 7. 
$\mathrm{U}_{\mathrm{ff}}=\mathrm{f}\left(\rho_{\text {sand }}, \rho_{\text {bio }}, \rho_{\text {bchar }}, \rho_{\mathrm{f}}, \mu, \mathrm{d}_{\text {sand }}, \mathrm{d}_{\text {bio }}, \mathrm{d}_{\text {bchar }}, \mathrm{g}\right)$

The Buckingham $\pi$ theorem allows a function expressed in dimensional parameters to be converted to dimensionless parameters. The parameters of Eq. (7) can be placed into five (n-m) dimensionless groups or dimensionless numbers $\pi$. Here, $\mathrm{n}=10$ is the number of parameters that influence the final fluidization velocity of a binary mixture, and $\mathrm{m}=3$ is the number of fundamental dimensions (mass, $\mathrm{M}$, length, $\mathrm{L}$, and time, $\mathrm{t})$.

The complete set of dimensionless numbers $\pi$ was established from three physical variables ( $\rho_{\text {bio, }} \mu$, and $\left.d_{\text {sand }}\right)$. Except for the dependent variable $\left(U_{\mathrm{ff}}\right)$, other variables could have been chosen. These are equivalent, however, as one set can be transformed into another [23]. The generic equation for the dimensionless groups is

$\pi_{i}=\rho_{\text {bio }}^{a} \mu^{b} d_{\text {sand }}^{c} Y=\left(\frac{M}{L^{3}}\right)^{a}\left(\frac{M}{L t}\right)^{b}(L)^{c} H_{j}=M^{0} L^{0} t^{0}$

Where $\pi_{i}$ is the dimensionless group, a, b, and $\mathrm{c}$ are the parameters to be found, $Y$ represents other physical quantities ( $\left.\mathrm{U}_{\mathrm{ff}}, \rho_{\text {sand }}, \rho_{\mathrm{bchar}}, \rho_{\mathrm{fluid}}, \mathrm{d}_{\mathrm{bio}}, \mathrm{d}_{\mathrm{bchar}}, \mathrm{g}\right)$, and $H_{j}$ represents the fundamental dimensions of the variables $\mathrm{U}_{\text {ff, }} \rho_{\text {sand }}, \rho_{\text {bchar }}, \rho_{\text {fluid }}, \mathrm{d}_{\text {bio }}, \mathrm{d}_{\text {bchar }}$, and $\mathrm{g}$.

The mass fraction of biomass ( $\mathrm{w}_{\mathrm{bio}}$ ) and biochar $\left(\mathrm{w}_{\mathrm{bchar}}\right)$ were used for the dimensionless numbers $\pi$, given its importance in determining the final fluidization velocity. The seven dimensionless groups established by the Buckingham $\pi$ method plus biomass and biochar mass fraction were

$$
\begin{aligned}
& \pi_{1}=\frac{\rho_{\text {sand }}}{\rho_{\text {bio }}} \\
& \pi_{2}=\frac{\rho_{\text {bchar }}}{\rho_{\text {bio }}} \\
& \pi_{3}=\frac{\rho_{f}}{\rho_{\text {bio }}} \\
& \pi_{4}=\frac{d_{\text {bio }}}{d_{\text {sand }}} \\
& \pi_{5}=\frac{d_{\text {bchar }}}{d_{\text {sand }}} \\
& \pi_{6}=\frac{\rho_{\text {bio }}^{2} d_{\text {sand }}^{3} g}{\mu^{2}}
\end{aligned}
$$


$\pi_{7}=w_{\text {bio }}$

$\pi_{8}=w_{b c h a r}$

$\pi_{9}=\frac{\rho_{\text {bio }} d_{\text {sand }} U_{f f}}{\mu}$

The relationship between these dimensionless groups is an essential step in developing a model. The correlations shown in Table 3 were found from a random or pre-existing association of dimensionless groups, and they are the ones that had the smallest prediction error.

Table 3 Dimensionless correlation

The prediction errors were calculated from the absolute relative difference between the calculated and experimental final fluidization velocity, and it was called the discrepancy (Eq. 24).

$\operatorname{DCP}(\%)=\frac{100 \mathrm{Abs}\left(U_{f f(\exp )}-U_{f f(c a l c)}\right)}{U_{f f(\exp )}}$

\section{Results and discussion}

\subsection{Fluidization patterns}

In experiments carried out with ternary mixtures of sand, sisal residue, and biochar, a behavior very similar to the first fluidization pattern proposed by Formisani et al. [16] was observed, with the formation of a small fluidized layer of biomass and biochar particles in the upper region of the bed. As a result of segregation, the sand particles at the top of the bed travel down as far as the gas velocity is increased. These particles form a fixed intermediate layer between the bubbling layer at the top of the bed and the original homogeneous mixture at the bottom of the column. This segregation process caused deviations in the rate of pressure drop from the typical curve of a fixed bed, and the superficial gas velocity of the gas was called the initial fluidization velocity $\left(\mathrm{U}_{\mathrm{if}}\right)$. Over $\mathrm{U}_{\mathrm{if}}$, the particles of the fluidization front gradually travel downward, and the height of the original homogeneous mixture located at the bottom of the column, which is not yet fluid, decreases progressively as the gas velocity is increased. A continuous increase in the gas superficial gas velocity causes the bed's total mass to be suspended and the final level of pressure drop to be reached. Subsequent increases in the gas superficial gas velocity cause the particles' rearrangements until the pressure drop is constant and reaches a state of complete fluidization, called final fluidization velocity ( $\left.\mathrm{U}_{\mathrm{ff}}\right)$. Tests $4,8,12,16,20$, and 21 represent the first fluidization pattern when the biochar is the mixture's 
component with the lowest density and the smallest particle size (as seen in Table 2). According to Formiasi et al. [24, 25], the results of tests 17-19, 22, 23, 26, and 27 (approximately constant sizes) are consistent with the first fluidization pattern.

Formisani et al. [16] showed that the second fluidization pattern occurs when the denser particle is also the smaller one, which was observed in experimental cases $3,7,11,15$, and 24 , shown in Table 2 . In this context, the fluidization front develops in the bed bottom with denser particles. Initially, the entire bed is raised, and a small horizontal space is created between it and the gas distributor. The slower particles begin to precipitate and form a bubbling layer at the bottom of the column. Simultaneously, the less dense component comes together as a fixed layer on top of the bed. An additional increase in the gas velocity promotes the growth of two segregated layers until the gas supports the entire bed, and the three solids mix again to a certain extent.

Tests 1, 2, 5, 6, 9, 10, 13, 14, and 25 did not follow the premises of Formiasi et al. [16] regarding fluidization patterns, considering that the smallest particle is not the one with the lowest or highest density (Table 2).

\subsection{Fluidization behavior}

Figs. (4-9) show the fluidization and defluidization curves involving pressure drop versus the gas superficial gas velocity for ternary systems composed of sand, sisal residue, and biochar. To better understand these fluidizations' dynamics and assess the influence of sisal residue and biochar on the process, the tests in Table 2 were organized into groups and subgroups listed in Table 4.

Table 4 Grouping of testes. The $\rho_{\text {bio }} / \rho_{\text {sand }}=0.67$ and $\rho_{\text {bchar }} / \rho_{\text {sand }}=0.24$ were kept constants for all tests

Fig. 4 shows the fluidization curve of four representatives of subgroup 1A (tests 1, 4, 13, and 16), on $\mathrm{d}_{\text {bio }} / \mathrm{d}_{\text {sand }}$ e $\mathrm{w}_{\text {bio }} / \mathrm{w}_{\text {bchar }}=1$, and particle sizes of 0.66 and $0.95 \mathrm{~mm}$ and fractions masses of 0.05 and 0.08 .

Fig. 4 Pressure drop versus superficial gas velocity for sand, sisal residue and biochar mixture. Subgroup 1A: (a) test $1\left(d_{\text {sand }}=0.66 \mathrm{~mm} ; d_{\text {bio }}=0.66 \mathrm{~mm} ; w_{\text {bio }}=0.05 ; w_{\text {bchar }}=0.05\right) ;(b)$ test $4\left(d_{\text {sand }}=0.95 \mathrm{~mm}\right.$; $d_{\text {bio }}$ $\left.=0.95 \mathrm{~mm} ; \mathrm{w}_{\text {bio }}=0.05 ; \mathrm{w}_{\mathrm{bchar}}=0.05\right) ;(\mathrm{c})$ test $13\left(\mathrm{~d}_{\text {sand }}=0.66 \mathrm{~mm} ; \mathrm{d}_{\text {bio }}=0.66 \mathrm{~mm} ; \mathrm{w}_{\text {bio }}=0.08 ; \mathrm{w}_{\text {bchar }}=\right.$ $0.08) ;(d)$ test $16\left(d_{\text {sand }}=0.95 \mathrm{~mm} ; d_{\text {bio }}=0.95 \mathrm{~mm} ; \mathrm{w}_{\text {bio }}=0.08 ; \mathrm{w}_{\text {bchar }}=0.08\right)$ 
Typical curves of the fluidization behavior with segregation due to deviations in the initial trajectories of fixed bed pressure drop are shown in Fig. 4 (b, c, and d). The fluidization curve is shown in Fig. 4 (a) seems to be an exception to the general behavior of subgroup 1A, in which the variation in pressure drop is typical of a fixed bed. On the other hand, Fig. 4 ( $a$ and $b$ ) shows the segregation process due to the increase of sand and biomass particle size. The slopes of the curves decreased with increasing particle size, indicating that the porosity of the mixture also increased, and slopes that decreased with the largest particle size are evident in Fig. 4 (c and d).

The curves in Fig. 4 (c and d) showed more intense segregations than those in Fig. 4 (a and b), and this result coincided with the largest mass fractions of biomass and biochar. Besides, segregation decreased as the particle size increased, when the materials' mass fractions were the highest (Fig. 4 (c and d)).

The biomass and biochar mass fraction influence on the fluidization dynamics can be seen in Fig. 4 (a and c) and (b and d). Fig. 4 (a and c) represents fluidization with smaller particles $(0.66 \mathrm{~mm})$ and Fig. 4 (b and d) with larger particles $(0.95 \mathrm{~mm})$. In these cases, the increase in the mass fraction of the particles made the fluidization less stable. However, the difference is very subtle when considering the largest particle. Fig. 4 (a) shows that the pressure drop variation was similar to that of a homogeneous fixed bed up to a velocity of $0.302 \mathrm{~m} / \mathrm{s}$, followed by a smooth and stable transition to the fully fluidized bed. From another perspective, Fig. 4 (c) shows a segregated bed at a low superficial gas velocity $(0.075 \mathrm{~m} / \mathrm{s})$, with subsequent fluctuation in the pressure drop as the gas velocity increases. The segregations showed in Fig. 4 (b and d) are lighter than the previous ones, but showed the same growth trend, when the mass fraction increased to 0.08 .

The fluidization hydrodynamics of four representatives of subgroup $1 \mathrm{~B}$ (tests 9, 12, 23 and 26) in the ratio $\mathrm{d}_{\text {bio }} / \mathrm{d}_{\text {sand }}=1$ and $\mathrm{w}_{\text {bio }} / \mathrm{w}_{\text {bchar }}<1$, with particle sizes of $0.66 \mathrm{~mm}, 0.95 \mathrm{~mm}$ and $0.80 \mathrm{~mm}$ and mass fractions of $0.035,0.05,0.065,0.08$ and 0.095 are shown in Fig.5.

Fig. 5 Pressure drop versus superficial gas velocity for a sand, sisal residue and biochar mixture. Subgroup 1B: (a) test $9\left(d_{\text {sand }}=0.66 \mathrm{~mm} ; d_{\text {bio }}=0.66 \mathrm{~mm} ; \mathrm{w}_{\text {bio }}=0.05 ; \mathrm{w}_{\text {bchar }}=0.08\right) ;(b)$ test $12\left(d_{\text {sand }}=0.95 \mathrm{~mm} ; d_{\text {bio }}\right.$ $\left.=0.95 \mathrm{~mm} ; \mathrm{w}_{\text {bio }}=0.05 ; \mathrm{w}_{\text {bchar }}=0.08\right) ;(\mathrm{c})$ test $23\left(\mathrm{~d}_{\mathrm{sand}}=0.80 \mathrm{~mm} ; \mathrm{d}_{\text {bio }}=0.80 \mathrm{~mm} ; \mathrm{w}_{\text {bio }}=0.065 ; \mathrm{w}_{\mathrm{bchar}}=\right.$ $0.095) ;(\mathrm{d})$ test $26\left(\mathrm{~d}_{\mathrm{sand}}=0.80 \mathrm{~mm} ; \mathrm{d}_{\text {bio }}=0.80 \mathrm{~mm} ; \mathrm{w}_{\text {bio }}=0.035 ; \mathrm{w}_{\text {bchar }}=0.065\right)$ 
The particle size influence on the fluidization process is represented in Fig. 5 ( $a$ and $b$ ) to biochar fractions higher than that in the sand. In this context, the particles' segregation decreased as the particle size increased from $0.66 \mathrm{~mm}$ to $0.95 \mathrm{~mm}$. The small value of initial fluidization velocity with subsequent deviation from the fixed bed curve is shown in Fig. 5 (a). The test's visual characterization did not classify the mixture in one of the fluidization patterns described previously since the smaller particle had intermediate density. Fig. 4 (a and c) and Fig. 5 (a) were analyzed together as a way to evaluate the influence of the mass fraction of biomass and biochar in the fluidization process of particles with constant sizes $\left(\mathrm{d}_{\mathrm{sand}}=0.66 \mathrm{~mm}, \mathrm{~d}_{\mathrm{bchar}}=\right.$ $0.78 \mathrm{~mm}$ and 5:5, 8:8 and 5:8 biomass to biochar fractions). In these tests, it was possible to observe an increase in segregation due to the increase in the particles' mass fraction; however, the most significant segregation occurred when the mass fractions were the highest. In contrast, Fig. 4 (b and c) and 5 (b) showed light segregation for larger particles $(0.95 \mathrm{~mm})$, even for high mass fractions of biomass and biochar. This behavior is related to the increase in bed porosity due to the existence of larger particles, regardless of the influence of mass fractions.

The fluidization dynamics of sand, sisal residue and biochar of four representatives of subgroup 1C (tests $3,15,21$ and 24$)$, for the ratio $\mathrm{d}_{\text {bio }} / \mathrm{d}_{\text {sand }}=1$ and $\mathrm{w}_{\text {bio }} / \mathrm{w}_{\text {bchar }}>1$, with particles of $0.66 \mathrm{~mm}, 0.95 \mathrm{~mm}$ and 0.80 $\mathrm{mm}$, in addition to the mass fractions of $0.035,0.05,0.065,0.08$ and 0.095 are shown in Fig. 6.

Fig. 6 Pressure drop versus superficial gas velocity for sand, sisal residue and biochar mixture. Subgroup $1 C$ : (a) test $5\left(d_{\text {sand }}=0.66 \mathrm{~mm} ; d_{\text {bio }}=0.66 \mathrm{~mm} ; w_{\text {bio }}=0.08 ; w_{\text {bchar }}=0.05\right) ;(b)$ test $8\left(d_{\text {sand }}=0.95 \mathrm{~mm}\right.$; $d_{\text {bio }}$ $\left.=0.95 \mathrm{~mm} ; \mathrm{w}_{\text {bio }}=0.08 ; \mathrm{w}_{\text {bchar }}=0.05\right) ;(\mathrm{c})$ test $22\left(\mathrm{~d}_{\mathrm{sand}}=0.80 \mathrm{~mm} ; \mathrm{d}_{\text {bio }}=0.80 \mathrm{~mm} ; \mathrm{w}_{\text {bio }}=0.095 ; \mathrm{w}_{\text {bchar }}=\right.$ $0.065) ;(\mathrm{d})$ test $27\left(\mathrm{~d}_{\mathrm{sand}}=0.80 \mathrm{~mm} ; \mathrm{d}_{\mathrm{bio}}=0.80 \mathrm{~mm} ; \mathrm{w}_{\mathrm{bio}}=0.065 ; \mathrm{w}_{\mathrm{bchar}}=0.035\right)$

The influence of particle size on bed stability can be seen again in Fig. 6 (c and d), whose graphs are similar to those found in Fig. 5 (c and d), indicating that the smallest segregation is associated with the largest particle size, regardless of the mass fraction of particle. The fluidization dynamics shown in Fig. 6 is different from the previous ones for a particle size of $0.66 \mathrm{~mm}$. The pressure drops remained with fixed bed characteristics in the range of $0-0.252 \mathrm{~m} / \mathrm{s}$ when the biochar's mass fraction was the lowest. For higher velocity, small deviations appeared regularly, falling below the imaginary fixed bed line. This behavior can be explained by the probable formation of a small fluidized layer at the bottom of the bed, which suddenly increased in size when the superficial gas velocity increased from $0.302 \mathrm{~m} / \mathrm{s}$ to $0.327 \mathrm{~m} / \mathrm{s}$. At that point, a 
small layer of particles was kept attached to the top of the bed, which was slowly dissolved until the medium remained completely fluidized. This behavior is characteristic of a slugging bed [26], in which the size of the gas bubbles increases as they rise through the bed, approaching the cross-section of the fluidizer. The bed is divided into regions with alternating dense and less dense phases [27]. The molecules were reorganized, and the bed remained completely fluidized from the superficial gas velocity of $0.50 \mathrm{~m} / \mathrm{s}\left(\mathrm{U}_{\mathrm{ff}}\right)$. This phenomenon was not observed in Fig. 4 (a and b) and Fig. 5 (a), whose particle size was also 0.66 $\mathrm{mm}$. This fact indicates that this phenomenon can occur on a larger scale when the fraction of biochar is lower than that of biomass.

Fig. 6 ( $a$ and $b$ ) curves showed a behavior opposite to the Fig. 5 ( $a$ and $b$ ) curves as the increase in the biomass and sand sizes resulted in a small segregation increase when the fraction of biochar was lower than that of biomass.

The fluidization dynamics of the ternary mixture of four representatives of subgroup 2A (tests $2,14,20$, and 25 ), for the ratio $\mathrm{d}_{\mathrm{bio}} / \mathrm{d}_{\mathrm{sand}}<1$ and $\mathrm{w}_{\text {bio }} / \mathrm{w}_{\text {bchar }}=1$, with particle sizes of $0.51 \mathrm{~mm}, 66 \mathrm{~mm}, 80 \mathrm{~mm}, 85$ $\mathrm{mm}, 0.95 \mathrm{~mm}$ and $1.10 \mathrm{~mm}$ and mass fractions of $0.05,0.65$ and 0.08 are shown in Fig. 7 . Test 20 was the only one that fit the first fluidization pattern proposed by Formisani et al. [16].

Fig. 7 Pressure drop versus superficial gas velocity for sand, sisal residue and biochar mixture. Subgroup 2A: (a) test $2\left(d_{\text {sand }}=0.95 \mathrm{~mm} ; d_{\text {bio }}=0.66 \mathrm{~mm} ; \mathrm{w}_{\text {bio }}=0.05 ; \mathrm{w}_{\text {bchar }}=0.05\right) ;(b)$ test $14\left(\mathrm{~d}_{\text {sand }}=0.95 \mathrm{~mm} ; d_{\text {bio }}\right.$ $\left.=0.66 \mathrm{~mm} ; \mathrm{w}_{\text {bio }}=0.08 ; \mathrm{w}_{\mathrm{bchar}}=0.08\right) ;(\mathrm{c})$ test $20\left(\mathrm{~d}_{\text {sand }}=1.10 \mathrm{~mm} ; \mathrm{d}_{\text {bio }}=0.80 \mathrm{~mm} ; \mathrm{w}_{\text {bio }}=0.065 ; \mathrm{w}_{\mathrm{bchar}}=\right.$ $0.065) ;(\mathrm{d})$ test $25\left(\mathrm{~d}_{\mathrm{sand}}=0.85 \mathrm{~mm} ; \mathrm{d}_{\text {bio }}=0.51 \mathrm{~mm} ; \mathrm{w}_{\text {bio }}=0.065 ; \mathrm{w}_{\text {bchar }}=0.065\right)$

The mass fraction increase from 0.05 to 0.08 caused a slight increase in the mixture segregation during fluidization, when the sand particle size was the largest, as can be seen in Fig. 7 ( $a$ and b). This effect also occurred on a smaller scale in (Fig. 4 (a and b)), when the size of each particle type was constant. The increase in the mass fraction of sand caused a subtle increase in segregation, but this effect was more significant when the mass fractions were the largest. The larger sand size in test 20 (Fig. 7 (c)) caused greater instability in the bed after the highest pressure drop, when the mass fractions were intermediate (0.065). In this case, the bed remained fixed and effectively mixed until reaching the maximum pressure drop and sequentially part of the bed fluidized, and the pressure drop decreased. From the superficial gas velocity of $0.478 \mathrm{~m} / \mathrm{s}$, the bed's fixed portion slowly fluidized as the gas velocity increased until the pressure 
drop began to fluctuate slowly around the final fluidization velocity. The increase in the sand's particle size did not help increase the stability in the partially fluidized region. However, it increased the porosity of the fixed bed. This result can be justified by the higher slope of the pressure drop lines when analyzing Fig. 7 (a) and Fig. 4 (a).

The fluidization dynamics of the mixture with smaller particles $\left(\mathrm{d}_{\mathrm{sand}}=0.80 \mathrm{~mm}\right.$ and $\left.\mathrm{d}_{\mathrm{bio}}=0.51 \mathrm{~mm}\right)$ and intermediate-mass fractions $(0.065)$ is represented in Fig. 7 (d). These mixing conditions did not produce significant effects in tests 2 and 14 (Fig. 7 (a and b)) when the size of sand and biomass particles was the largest. Otherwise, the fluidization curve was seen in Fig. 7 (d) is more stable than the other and shows no signs of segregation. Consequently, there is an optimal fluidization condition in which segregation is minimized, for $\mathrm{d}_{\mathrm{bio}} / \mathrm{d}_{\text {sand }}<1$ and $\mathrm{w}_{\mathrm{bio}} / \mathrm{w}_{\mathrm{bchar}}=1$.

The fluidization dynamics of four representatives of subgroup $3 \mathrm{~A}$ (tests $3,15,21$ and 24 ), for ratio $\mathrm{d}_{\text {bio }} / \mathrm{d}_{\text {sand }}>$ 1 and $\mathrm{w}_{\mathrm{bio}} / \mathrm{w}_{\mathrm{bchar}}=1$, with particle sizes of $0.51 \mathrm{~mm}, 0.66 \mathrm{~mm}, 0.80 \mathrm{~mm}, 0.95 \mathrm{~mm}$ and $1.10 \mathrm{~mm}$, and the mass fractions of $0.05,0.65$ and 0.08 are shown in Fig. 8. Test 21 (Fig. S5 (c)) is shown as the only one that fits the first fluidization pattern proposed by Formisani et al. [16].

Fig. 8 Pressure drop versus superficial gas velocity for sand, sisal residue and biochar mixture. Subgorup $3 \mathrm{~A}$ : (a) test $3\left(\mathrm{~d}_{\text {sand }}=0.66 \mathrm{~mm} ; \mathrm{d}_{\text {bio }}=0.95 \mathrm{~mm} ; \mathrm{w}_{\text {bio }}=0.05 ; \mathrm{w}_{\text {bchar }}=0.05\right) ;(\mathrm{b})$ test $15\left(\mathrm{~d}_{\text {sand }}=0.66 \mathrm{~mm} ; \mathrm{d}_{\text {bio }}\right.$ $\left.=0.95 \mathrm{~mm} ; \mathrm{w}_{\text {bio }}=0.08 ; \mathrm{w}_{\text {bchar }}=0.08\right) ;(\mathrm{c})$ test $21\left(\mathrm{~d}_{\mathrm{sand}}=0.80 \mathrm{~mm} ; \mathrm{d}_{\text {bio }}=1.10 \mathrm{~mm} ; \mathrm{w}_{\text {bio }}=0.065 ; \mathrm{w}_{\text {bchar }}=\right.$ $0.065) ;(d)$ test $24\left(d_{\text {sand }}=0.51 \mathrm{~mm} ; d_{\text {bio }}=0.80 \mathrm{~mm} ; \mathrm{w}_{\text {bio }}=0.065 ; \mathrm{w}_{\text {bchar }}=0.065\right)$

The comparison between Figs. 7 and 8 shows that the increase in fluidization stability occurs when the largest biomass particle size is used, regardless of the biomass and biochar mass fractions. The lowest final fluidization velocity and the smallest differences between the final fluidization velocity and the initial segregation velocity are shown in Fig. 8. The mass fractions effect on the fluidization dynamics can be observed by comparing the graphs in Fig. 8 ( $a$ and $b$ )) for the biomass particle size larger than that of sand. The bed was well mixed when the largest biomass and biochar mass fractions were used, and all fluidization velocities were the same $\left(U_{\text {if }}, U_{\mathrm{ff}}, \mathrm{U}_{\mathrm{is}}\right.$, and $\left.\mathrm{U}_{\mathrm{fb}}\right)$. From the fluidization curve shown in Fig. 8 (b), the increase in the gas superficial gas velocity caused a progressive increase in the porosity of the fixed bed and a smooth transition to the fluidized bed. The same process occurred in defluidization, when the utterly fluidized medium was transformed into a homogeneous fixed bed at the same superficial gas velocity as the 
fluidization. The mixture homogeneity, seen in Fig. 8 (b), decreased when the particle size of the sand and biomass increased for biomass and biochar fractions with intermediate values (Fig. 8 (c)). In that case, the biochar begins to fluidize at very low gas velocities at the top of the bed. This fluidization pattern also considers forming a compact layer of denser particles just below the fluidized layer and a fixed and homogeneous layer at the bottom of the bed. The increase in the gas's superficial gas velocity caused the particles located in front of the fluidization to gradually move to the bottom of the bed, progressively increasing the number of particles involved in the fluidization. The highest pressure drop value was reached at $0.554 \mathrm{~m} / \mathrm{s}$. The increase in the superficial gas velocity smoothly reduced the particle's inertial force, and the final fluidization was quickly achieved.

The fluidization dynamics for smaller particles $\left(\mathrm{d}_{\mathrm{sand}}=0.51 \mathrm{~mm}\right.$ and $\left.\mathrm{d}_{\mathrm{bio}}=0.80 \mathrm{~mm}\right)$ and intermediate-mass fractions (0.065) are shown in Fig. S5 (d). These conditions of the mixture did not produce significant effects in test 3 (Fig. 8 (a)) when the particle size of the sand and biomass was larger. Otherwise, in Fig. 8 (d), the fluidization shows small segregation of $0.201 \mathrm{~m} / \mathrm{s}$, with part of the fluidized bed, and at $0.403 \mathrm{~m} / \mathrm{s}$, the bed became completely fluidized. Despite test 15 (Fig. 8 (b)) presenting a fluidization dynamic closer to a single component mixture, test 24 (Fig. 8 (d)) showed the lowest final fluidization velocity and initial segregation.

Two tests for $\mathrm{d}_{\mathrm{bio}} / \mathrm{d}_{\mathrm{sand}}<1$ : test $10\left(\mathrm{w}_{\mathrm{bio}} / \mathrm{w}_{\mathrm{bchar}}<1\right)$ and test $6\left(\mathrm{w}_{\mathrm{bio}} / \mathrm{w}_{\mathrm{bchar}}>1\right)$, Fig. $8(\mathrm{a}$ and $\mathrm{b})$; and two tests for $\mathrm{d}_{\text {bio }} / \mathrm{d}_{\text {sand }}>1$ : test $11\left(\mathrm{w}_{\text {bio }} / \mathrm{w}_{\text {bchar }}<1\right)$ and test $7\left(\mathrm{w}_{\text {bio }} / \mathrm{w}_{\text {bchar }}>1\right)$, Fig. $9(\mathrm{c}$ and d $)$ were combined and are shown in Fig. 9.

Fig. 9 Pressure drop versus superficial gas velocity for sand, sisal residue and biochar mixture. Subgroup 2B: (a) test $10\left(\mathrm{~d}_{\text {sand }}=0.95 \mathrm{~mm} ; \mathrm{d}_{\text {bio }}=0.66 \mathrm{~mm} ; \mathrm{w}_{\text {bio }}=0.05 ; \mathrm{w}_{\text {bchar }}=0.08\right)$; Subgroup 2C: $(\mathrm{b})$ test $6\left(\mathrm{~d}_{\text {sand }}\right.$ $\left.=0.95 \mathrm{~mm} ; \mathrm{d}_{\text {bio }}=0.66 \mathrm{~mm} ; \mathrm{w}_{\text {bio }}=0.08 ; \mathrm{w}_{\text {bchar }}=0.05\right)$; Subgroup $3 \mathrm{~B}:(\mathrm{c})$ test $11\left(\mathrm{~d}_{\text {sand }}=0.66 \mathrm{~mm} ; \mathrm{d}_{\text {bio }}=\right.$ $\left.0.95 \mathrm{~mm} ; \mathrm{w}_{\text {bio }}=0.05 ; \mathrm{w}_{\text {bchar }}=0.08\right)$; Subgroup $3 \mathrm{C}:(\mathrm{d})$ test $7\left(\mathrm{~d}_{\text {sand }}=0.66 \mathrm{~mm} ; \mathrm{d}_{\text {bio }}=0.95 \mathrm{~mm} ; \mathrm{w}_{\text {bio }}=0.08\right.$; $\left.\mathrm{W}_{\mathrm{bchar}}=0.05\right)$

The influence of the mass fraction of biomass and biochar on the fluidization to sand particles larger than the biomass is graphically represented in Fig. 9 ( $a$ and b). The behavior of the mass fraction involving the same particle sizes as in Fig. 9 ( $a$ and $b$ ) and mass fractions equal to 0.05 was analyzed and explained using Test 2 (Fig. 7 (a)). From Test 2, it is possible to observe the fluidization with small segregation between 
the particles, as previously identified. The segregation increased as the mass fraction of the biochar increased from 0.05 to 0.08 (Fig. 9 (a)), although the system has reached a lower final fluidization velocity.

However, Fig. 9 (b) shows that segregation has become much more intense and shows signs of slugging behavior when the biomass fraction is higher than that of the biochar. By increasing the mass fraction of biomass and biochar to 0.08 (Fig. 7 (b)), the mixture presented discrete segregation but with a very high final fluidization velocity.

The mass fraction's influence was also evaluated when the biomass particle size was larger than that of sand (Fig. 9 (c and d)). Tests 3 and 15 (Fig. 8 (a and b) were used as a reference, as the mass fractions were 0.05 and 0.08 . Fluidization was smoother when the mass fraction of the biochar increased from 0.05 to 0.08 , with the biomass fraction of 0.05 , although a discrete slugging behavior was found. In this situation, the final fluidization velocity was the highest. However, segregation was higher when the biomass mass fraction was increased to 0.08 , with a biochar mass fraction of 0.05 . The system was much more stable for biomass and biochar mass fraction at 0.08 (Fig. 8 (b)) and achieved a lower final fluidization velocity.

\subsection{Segregation behavior}

The ternary system fluidization process is complicated because of the higher possibility of interaction effects between the sand, biomass, and biochar particle size and mass fractions. In item 3.2, it was seen that the increase in particle size caused an increase in the segregation for mass fractions of $5 \%$ and $\mathrm{d}_{\text {bio }} / \mathrm{d}_{\text {sand }}=$ 1. However, Fig. 4 (a, b, c and d) show that the segregation decreased when the mass fractions were $8 \%$. Conversely, increasing biomass and biochar fractions also increases segregation, regardless of the particle size. However, a small effect on the segregation levels was observed when only the biomass particle size was increased (Figs. 4 (a, b, c, and d), 6 (a and b), and 7 (a and b)). These cases are a few examples of the synergy between the bed properties that have not yet been discussed in the literature, mainly in cylindrical beds.

Numerous experiments have been carried out in an attempt to analyze the segregation dynamics $[3,6,8$, 16]. In general, these studies indicate that the particle characteristics, such as density, shape, and sizes, must be the main factors that affect segregation. However, the segregation minimization by manipulating the operational variables of fluidization was not found in a previous study. Nevertheless, Tang and Puri [28] presented three methods to minimize segregation, including improving material properties, proper selection 
of handling equipment and operational parameters, and proper control of material handling environmental conditions. These authors considered that segregation would be minimized by narrowing size distribution, reducing absolute size, and avoiding irregularly shaped particles.

A more systematic study was carried out to evaluate the effects of fluidization variables on the segregation of a ternary mixture, considering that the best operating condition is the one that provides the lowest possible segregation [3]. This study involved statistical tools related to the effects of the variables and their interactions with segregation. In this paper, the segregation percentage (S) was used, and these values are found in Table 2 associated with each operational condition.

The variable operational significance on the segregation percentage was analyzed based on statistics, and the discussion is found in the supplementary material, item S1.0.

The main variable $\left(\mathrm{w}_{\mathrm{bchar}}\right)$, the first-order interactions $\left(\mathrm{d}_{\mathrm{sand}}-\mathrm{d}_{\mathrm{bio}}, \mathrm{d}_{\mathrm{sand}}-\mathrm{W}_{\mathrm{bio}}, \mathrm{d}_{\mathrm{bio}}-\mathrm{W}_{\mathrm{bchar}}, \mathrm{w}_{\mathrm{bio}}-\mathrm{W}_{\mathrm{bchar}}\right)$, and second-order interaction $\left(\mathrm{d}_{\text {sand }}-\mathrm{d}_{\text {bio }}-\mathrm{w}_{\text {bchar }}, \mathrm{d}_{\text {bio }}-\mathrm{w}_{\text {bio }}-\mathrm{w}_{\text {bchar }}\right)$ were found to be nonsignificant and were removed from the calculation.

Fig. 10 shows the three-dimensional surfaces plotted to study the interactions between six pairs of variables ( $\mathrm{d}_{\text {sand }}$ and $\mathrm{d}_{\text {bio }} ; \mathrm{d}_{\text {sand }}$ and $\mathrm{w}_{\text {bio }} ; \mathrm{d}_{\text {sand }}$ and $\mathrm{w}_{\text {bchar }} ; \mathrm{d}_{\text {bio }}$ and $\mathrm{w}_{\text {bio }}, \mathrm{d}_{\text {bio }}$ and $\mathrm{w}_{\text {bchar }}, \mathrm{w}_{\text {bio }}$ and $\mathrm{w}_{\text {bchar }}$ ).

Fig. 10 Response surface representing the combined effects on the segregation percentage between sand particle size, sisal residue particle size, sand/sisal residue mass fraction, and sand/biochar mass fraction

The combined effects of the sand particle size and sisal residue particle size were used to obtain the segregation percentage, and the results are shown in Fig. 10 (a). The segregation percentage decreased as the sand particle size decreased, and the sisal residue particle size increased. This result is not in line with the work of Singh et al. [29], which showed that the smallest particle size contributes to a well-mixed bed. However, the result is shown in Fig. 10 (a) seems to be correct if it is considered that the decrease in the sand particle size and the increase in the biomass particle size tend to compensate for the higher and lower density, respectively. Fig. 10 (b and c) shows a similar result, with the segregation percentage decreasing when the sand particle size decreased from $0.95 \mathrm{~mm}$ to $0.66 \mathrm{~mm}$, and the sisal residue and biochar mass fractions decreased from 0.08 to 0.05 . This result also diverges from the literature results for individual variations in ternary fluidization [6]. For these authors, segregation decreases when mass fractions increase. Shao et al. [8] presented a similar result as our study, in which the increase in the biomass fraction decreases 
the mixture quality. These authors evaluated binary and ternary mixture with more than one biomass and concluded that the proportion of waste particles to the bed material might be the main factor that affects the mixture behavior.

Nevertheless, the density has a more significant influence than its size and shape among the waste particles.

Fig. 10 (d) shows that segregation percentage decreased when sisal residue mass fraction decreased regardless of its particle size. However, Fig. 10 (e) shows that segregation percentage decreased as the sisal residue particle size increased, regardless of the value of biochar mass fraction. This result indicates that sisal residue mass fraction has a more significant influence than biochar mass fraction. This conclusion can be confirmed from Fig. 10 (f), which shows that the segregation percentage decreased when the sisal residue mass fraction decreased, regardless of the value of biochar mass fraction. In this case, the sisal residue's density is higher than that of biochar, and it is necessary to reduce the mass fraction of the sisal residue to increase the mixture quality.

\section{$3.4 U_{f f}$ behavior}

The reduction of the final fluidization velocity is another essential part of the optimization, which will be evaluated in this section. It represents the velocity at which the bed in transition remains completely fluidized $[15,24]$.

In ternary fluidization of sand, sisal residue, and biochar, the final fluidization velocity was analyzed for the sand and sisal residue particle sizes, and sisal residue and biochar mass fraction. The effects of the main variables and their interactions were determined using an experimental planning technique with a welladjusted quadratic model. The main variable ( $\left.\mathrm{w}_{\mathrm{bchar}}\right)$ and the first-order interactions $\left(\mathrm{d}_{\mathrm{sand}}-\mathrm{d}_{\mathrm{bio}}, \mathrm{d}_{\mathrm{sand}}-\mathrm{w}_{\mathrm{bio}}\right.$, $\mathrm{W}_{\text {bio }}-\mathrm{W}_{\mathrm{bchar}}$ ) were nonsignificant and were removed from the calculation (see supplementary material, item $\mathrm{S} 2.0)$.

Fig. 11 shows the three-dimensional surfaces that were plotted to study the interactions between six pairs of variables ( $\mathrm{d}_{\text {sand }}$ and $\mathrm{d}_{\text {bio }}$; $\mathrm{d}_{\text {sand }}$ and $\mathrm{w}_{\text {bio }} ; \mathrm{d}_{\text {sand }}$ and $\mathrm{w}_{\text {bchar }} ; \mathrm{d}_{\text {bio }}$ and $\mathrm{w}_{\text {bio }}, \mathrm{d}_{\text {bio }}$ and $\mathrm{w}_{\text {bchar, }}, \mathrm{w}_{\text {bio }}$ and $\mathrm{w}_{\text {bchar }}$ ).

Fig. 11 Response surface representing the combined effects on the final fluidization velocity between sand particle size, sisal residue particle size, sand/sisal residue mass fraction, and sand/biochar mass fraction 
The combined effects of the sand and sisal residue particle size were used to obtain the final fluidization velocity, and the results are shown in Fig. 11 (a). The final fluidization velocity decreased when the sand and sisal particle sizes decreased when the biomass and biochar mass fractions of $5 \%$, $d_{\text {sand }}$ of $0.95-0.66$ $\mathrm{mm}$, and $\mathrm{d}_{\mathrm{bio}}$ of $0.66-0.95 \mathrm{~mm}$ (Fig. 5 (a) and 8 (a)). On the other hand, the final fluidization velocity increased when the biomass and biochar mass fraction was at $8 \%$ and with the same variation in the particle sizes (Fig. 7 (b) and 8 (b)). In this case, the opposite behavior of the final fluidization velocity occurred due to the mass fractions' levels.

Fig. 11 (b) shows that the final fluidization velocity decreases when the sand particle size is reduced from $0.95 \mathrm{~mm}$ to $0.66 \mathrm{~mm}$, and sisal residue mass fractions are reduced from 0.08 to 0.05 . This case can be illustrated with the final fluidization velocity shown in Fig. 4 (a) and 9 (b).

The decrease in the final fluidization velocity was also shown in Fig. 11 (c) when the sand particle size and biochar mass fractions were reduced. However, using the smallest sand particle size, it can be noticed that the mass fraction of biochar has a lower impact on the final fluidization velocity compared to the sisal residue mass fraction. Fig. 4 (a) and 5 (a) are examples of reducing the final fluidization velocity caused by the decrease in the biochar mass fraction.

Fig. 11 (d) shows a region where the minimum final fluidization velocity is obtained when the sisal residue particle size is around the central point and the sisal residue mass fraction is below the central point.

Once again, the biochar mass fraction variation had a subtle influence on the final fluidization velocity (Fig. 11 (e)). This figure shows a region with the minimum final fluidization velocity when the biochar mass fraction is close to the central point, and sisal residue particle size is just below the central point.

Fig. 11 (f) shows that the final fluidization velocity decreases with the reduction of sisal residue mass fraction, and It presents a region of minimum value when biochar mass fraction is close to the central point.

The independent variables' effects on the final fluidization velocity were calculated according to the experimental planning technique. The calculation of these values has been performed from the variation average of an independent variable's responses. In this study, the sand particle size caused the most significant effect on the final fluidization velocity; when the particle size decreased from $0.95 \mathrm{~mm}$ to 0.66 $\mathrm{mm}$, the final fluidization velocity decreased by $0.12 \mathrm{~m} / \mathrm{s}$. This result can be associated with the reduction of segregation (Fig. 10 (a, b and c)), showing a better mixing at lower superficial gas velocities. The other 
significant effect on the final fluidization velocity was caused by the sisal residue mass fraction, which decreased the velocity by $0.07 \mathrm{~m} / \mathrm{s}$ when the mass fraction went from 0.08 to 0.05 . Again, this effect is associated with the reduction of segregation and an earlier bed homogenization. The decrease in the biomass particle size caused a reduction of final fluidization velocity by $0.05 \mathrm{~m} / \mathrm{s}$; however, this result is not related to the segregation reduction (Fig. 10 (a, d and e)). This result is related to the sisal residue's saddle-shaped, allowing sand to become trapped in the cavity. The decrease in the sisal residue particle size allowed trapping a smaller amount of sand, increasing the difference between the sand's density and the trapped biomass with sand.

Consequently, it can increase the segregation extent. On the other hand, by increasing the superficial gas velocity, the particle moved towards the bottom bed until the bed became fully fluidized. The effect of the biochar mass fraction was not significant for the initial fluidization velocity, but its interaction with the sand particle size was essential and, therefore, it should be considered. The final fluidization velocity decreased when the biochar mass fraction decreased, and the segregation reduction can also explain this result.

Up to this point, it can be affirmed that the minimization of the fluidization process cannot be achieved without the mutual evaluation of the final fluidization velocity and the segregation. The lowest levels of the independent variables caused the lowest values of the final fluidization velocity and the segregation. The sisal residue particle size was the exception to this behavior, and its decrease in size caused an increase in the segregation. The lower value of the sisal residue particle size does not significantly increase the segregation (Fig. 10). However, the optimal condition for fluidizing sand, sisal residue, and biochar concern all independent variables' lowest values. In these conditions, the calculated values of the final fluidization velocity and segregation percentage were $0.378 \mathrm{~m} / \mathrm{s}$ and $2.619 \%$, respectively (Table 2).

\subsection{Novel modeling of fluidization velocity}

The relationship between dimensionless groups is a critical step in model development. Although there is no specific rule for the logical model construction based on dimensionless groups, practice teaches us that the equation structures already established in the literature deserve to be investigated. Table 3 lists a series of equations (Eq. 18 to 23) that relate the dimensionless groups to each other and attributes to the constant $\mathrm{Ci}(\mathrm{i}=1$ to 8$)$ the importance of each term. The Ci constants' values were estimated by the quasi-Newton method based on the operational conditions shown in Table 2. 
Eq. 23 was the correlation with the lower discrepancy, resulting in Eq. 25:

$R e_{f f}^{*}=A\left[B+D A r^{* C 4}\right]$

Where:

$R e_{f f}^{*}=\frac{\rho_{f} d_{\text {sand }} U_{f f}}{\mu} \quad ; \quad A r^{*}=\frac{\rho_{f} \rho_{\text {bio }} d_{\text {sand }}{ }^{3} g}{\mu^{2}} \quad ; \quad A=\frac{\rho_{f}}{\rho_{\text {bio }}}$

$B=C 1 \frac{\rho_{\text {sand }}}{\rho_{\text {bio }}} \frac{d_{\text {bio }}}{d_{\text {sand }}}+C 2 \frac{\rho_{\text {bio }}}{\rho_{\text {bchar }}} \frac{d_{\text {bchar }}}{d_{\text {sand }}}+C 5 w_{\text {bio }}+C 6 w_{\text {bchar }} \quad ; \quad D=C 3 A^{1-C 4}$

$\mathrm{C} 1=7500 ; \mathrm{C} 2=-5000 ; \mathrm{C} 3=850 ; \mathrm{C} 4=0.624 ; \mathrm{C} 5=150900 ; \mathrm{C} 6=15000$

The number of Reynolds $R e_{f f}^{*}$ e Arquimedes $A r^{*}$ were based on the sand particle size and not on the effective particle size, as it is common in multicomponent fluidization.

Shao et al. [7] presented a model (Eq. 2) to predict the minimum fluidization velocity to a ternary mixture using effective particle density and size (Eq. 3 and 4). In this article, Eq. 2 was used to predict the final fluidization velocity to the ternary mixture of the sand, sisal residue, and biochar. The values of constants were estimated by the quasi-Newton method, based on the operational conditions shown in Table 2, where $\mathrm{C} 1=177, \mathrm{C} 2=-3.354$, and $\mathrm{C} 3=0.3064$.

Fig. 12 compares de measured and predicted final fluidization velocity for the mixture of sand, sisal residue, and biochar. The correlations developed for the final fluidization velocity in the present study (Eq. 25) and the one from Shao et al. [7] (Eq. 2) agreed well with the experimental data. Eq. 2 predicted the final fluidization velocity as a mean discrepancy of $9.6 \%$. It should be noted that this equation was developed to investigate the fluidization of irregular particles and its relative error was lower than in the previous investigation. However, when using the correlation proposed by the present study (Eq. 25) to predict the final fluidization velocities of these ternary mixture systems, the mean discrepancy of the predictions to the experiments was only $6.7 \%$. Although our model (Eq. 25) presents some deviations, it agrees with the experiments over a wide range of conditions.

Fig. 12 Predicted versus experimental final fluidization velocity for the tertiary mixture of sand, sisal residue, and biochar 


\section{Conclusions}

In this work, the fluidization behavior of a ternary mixture of sand, sisal residue, and biochar was studied. Experimental observations on the fluidization were conducted to determine the final fluidization velocities and segregation percentages in a cylindrical fluidized bed under ambient conditions. The tests were carried out in different rations of particle size and mass fraction $\left(\mathrm{d}_{\mathrm{bio}} / \mathrm{d}_{\mathrm{sand}}\right.$ and $\left.\mathrm{w}_{\mathrm{bio}} / \mathrm{w}_{\mathrm{bchar}}\right)$, and the effects of variables $\left(\mathrm{d}_{\text {sand }}, \mathrm{d}_{\text {bio }}, \mathrm{w}_{\text {bio, }}\right.$ and $\left.\mathrm{w}_{\text {bchar }}\right)$ and their interaction were shown from statistical analysis.

The trend of the effect of particle size and mass fraction on the final fluidization velocity was the same. The final fluidization velocity has occurred with the lowest values of the variables. On the other hand, the lowest segregation percentage was found when the sisal residue particle size was the largest, although the other variables were also in their lowest values. The phenomenon was associated with the shape of the sisal residue that allows sand to become trapped in the cavity. The aggregate of sisal and sand residue causes resistance to other particles' displacement, and the bed segregation decreased. Although the biomass particle size has opposite effects on the final fluidization velocity and mixture segregation, the best fluidization condition with the smallest particle size was observed.

The proposed correlation can satisfactorily predict the final fluidization velocity for a mixture of sand, sisal residue, and biochar in a fluidized bed.

Our study has potential applicability to biomass fluidized bed pyrolysis reactors' operation involving varying particle sizes over the complete range of operation.

\section{Acknowledgments}

The authors would like to acknowledge the support of the PPEQ. This study was financed in part by the Coordenação de Aperfeiçoamento de Pessoal de Nível Superior - Brasil (CAPES) -Finance Code 001.

\section{References}

[1] Mostafazadeh, A. K., Solomatnikova, O., Drogui, P., \& Tyagi, R.D.. A review of recent research and developments in fast pyrolysis and bio-oil upgrading. Biomass Conversion and Biorefinery, 8, 739-773 (2018). 
[2] Sharma, A., Wang, S., Pareek, V., Yang, H., Zhang, D.: CFD modeling of mixing/segregation behavior of biomass and biochar particles in a bubbling fluidized bed. Chemical Engineering Science, 106, 264-274 (2014).

[3] Olaofe, O.O., Buist, K.A., Deen, N.G., van der Hoef, M.A., Kuipers, J.A.M.: Segregation dynamics in dense polydisperse gas-fluidized beds. Powder Technology, 246, 695-706 (2013).

[4] Jena, H.M., Roy, G.K., Biswal, K.C.: Studies on pressure drop and minimum fluidization velocity of gas-solid fluidization of homogeneous well-mixed ternary mixtures in un-promoted and promoted square bed. Chemical Engineering Journal, 145, 16-24 (2008).

[5] Feng, R., Junguo Lia, J., Chenga, Z., Yangc, X., Fanga, Y.: Influence of particle size distribution on minimum fluidization velocity and bed expansion at elevated pressure. Powder Technology, 320, 27-36 (2017).

[6] Hong, T., Jung, E., Lee, D. H.: Segregation of glass beads in three-sectional tapered fluidized beds with ternary system. Powder Technology, 343, 342-349 (2019).

[7] Shao, Y., Ren, B., Jin, B., Zhong, W., Hu, H., Chen, X., Sha, C.: Experimental flow behaviors of irregular particles with silica sand in solid waste fluidized bed. Powder Technology. 234, 67-75 (2013).

[8] Shao, Y., Zhong, W., Yu, A.: Mixing behavior of binary and multicomponent mixtures of particles in waste fluidized beds. Powder Technology, 304, 73-80 (2016).

[9] Asif, M.: Predicting minimum fluidization velocities of multicomponent solid mixtures. Particuology, $11,309-316(2013)$.

[10] Formisani, B., Girimonte, R, Mancuso, L: Analysis of the fluidization process of particle beds at higt temperature. Chemical Engineering Science. 53 (5), 951-961 (1998).

[11] Mohammad-Javad, H-S-L., Navid, M.: Effect of Temperature on Fluidization Regimes. Chemical Engineering \& Technology. 37(9), 1593-1599 (2014).

[12] Pereira, T. O., Santos, D. B. P., Pires, C. A. M. Modeling and simulation of pyrolysis of sisal residue in transient regime. Research, Society and Development, 9 (3) (2020). 
[13] Jambeiro, T. A., Silva, M.F.S., Pereira, L.G.G., Vasconcelos, D.S., Silva, G.B., Figueirêdo, M.B., Lima, S.B., Pires, C.A.M.: Fast Pyrolysis of Sisal Residue in a Pilot Fluidized Bed Reactor. Energy \& fuels, 32(9), 9478-9492 (2018).

[14] Pillai, B.C., Rao, M.R.: Pressure drop and minimum fluidization velocities in air-fluidized beds. Indian Journal Technology, 9, 77-86 (1971).

[15] Formisani, B., Girimonte, R.: Experimental analysis of the fluidization process of binary mixtures of solids. Kona, 21, 66-75 (2003).

[16] Formisani, B., Girimonte, R., Vivacqua, V.: Fluidization of mixtures of two solids: a unified model of the transition to the fluidized state. AIChE Journal, 59(3), 729-735 (2013).

[17] Montgomery, D.C.: Design and Analysis of Experiment. John Wiley \& Sons, Inc. Eighth ed., ISBN 978-1118-14692-7 (2013).

[18] Palkar, R.R., Shilapuram, V.: Detailed parametric design methodology for hydrodynamics of liquidsolid circulating fluidized bed using design of experiments. Particuology, 31, 59-68 (2017).

[19] Pereira, L.G.G., \& Pires, C.A.M.: Bio-Oil Viscosity of Sisal Residue: Process and Temperature Influence. Energy \& Fuels, 32(4), 5115-5124 (2018).

[20] Vasconcelos, D., Batalha, G., Pereira, L.G., Pires, C.A.: Fluidization of binary mixtures of sisal residue and sand: A new model for deriving the final fluidization velocity. Particuology, 40, 10-22 (2018).

[21] Coltters, R., \& Rivas, A.: Minimum fluidization velocity correlations in particulate systems, Powder Technology, 147(1), 34-48 (2004).

[22] Zhong, W., Jin, B., Zhang, Y., Wang, X., Xiao, R.: Fluidization of biomass particles in a gas-solid fluidized bed. Energy \& Fuels, 22(6) 4170-4176 (2008).

[23] Olmos, E., Loubiere, K., Martina, C., Delaplace, G., Marca, A.: Critical agitation for microcarrier suspension in orbital shaken bioreactors: Experimental study and dimensional analysis. Chemical Engineering Science, 122, 545-554 (2015). 
[24] Formisani, B., Girimonte, R., Longo, T.: The fluidization pattern of density-segregating binary mixtures. Chemical Engineering Research and Design. 86, 344-348 (2008a).

[25] Formisani, B., Girimonte, R., Longo, T.: The fluidization process of binary mixtures of solids: Development of the approach based on the fluidization velocity interval. Powder Technology 185, 97108 (2008).

[26] Kunii D. and Levenspiel, O.: Fluidization engineering. R.E. Krieger Publ., Huntington (1969).

[27] Yang, W-C.: Handbook of fluidization and fluid-particle systems. Taylor \& Francis Group LLC, Pennsylvania, USA (2003).

[28] Tang, P., \& Puri, V.M.: Methods for Minimizing Segregation: A Review. Particulate Science and Technology, 22, 321-337 (2004).

[29] Singh, B.K., Roy, S., Buwa, V.V.: Dynamics of segregation and fluidization of binary mixtures in a cylindrical fluidized bed. AIChE Journal. 1-15 (2019). 
Figures

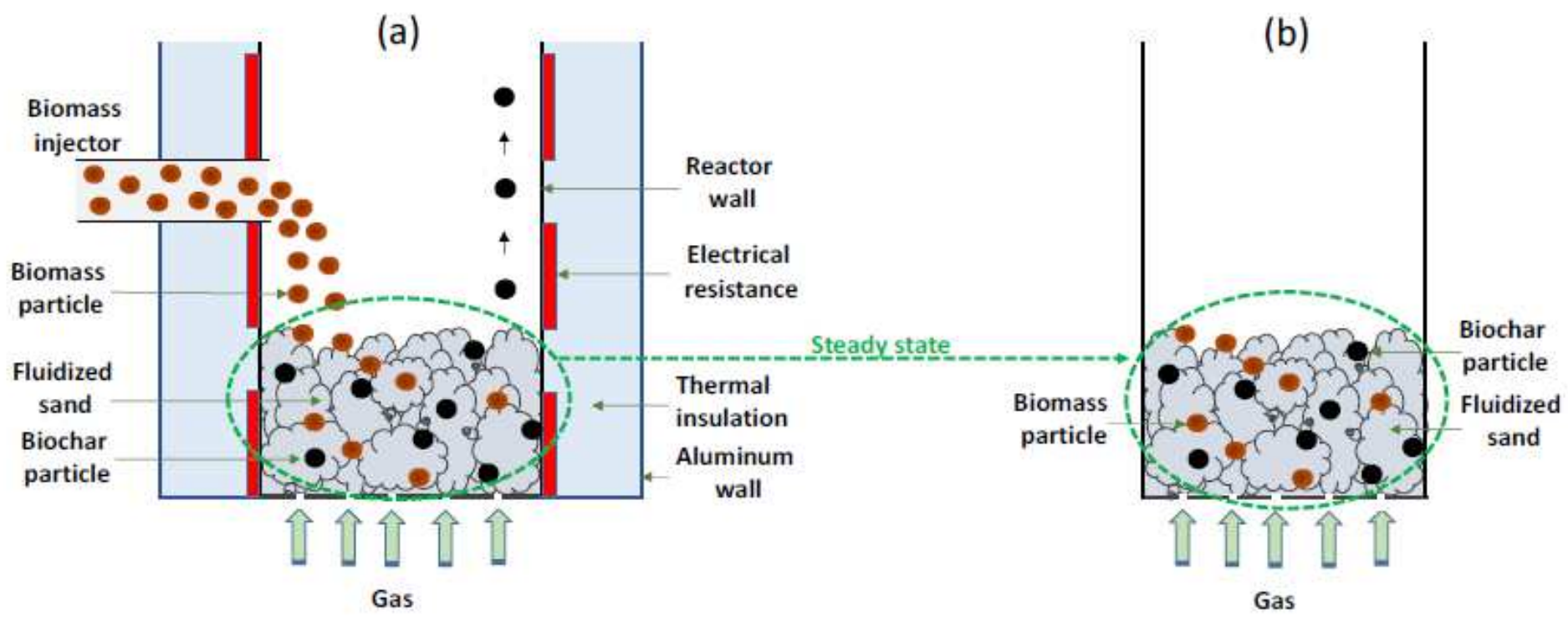

Figure 1

Fluidization of sand, biomass, and biochar: (a) in a continuous system (with reaction); (b) in a batch system (without reaction)

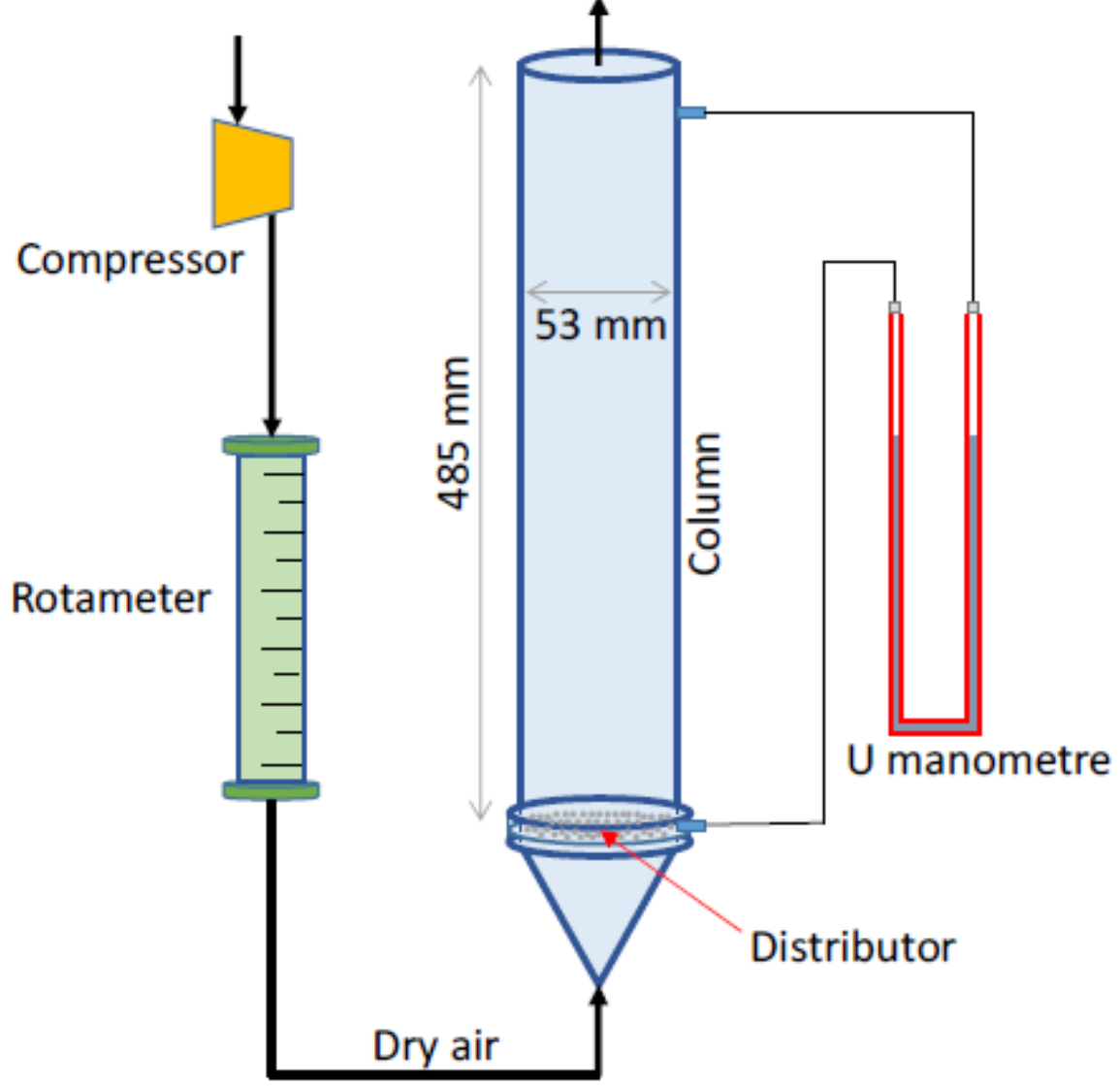

Figure 2 
Fluidization system

$\diamond$ Decreasing velocity

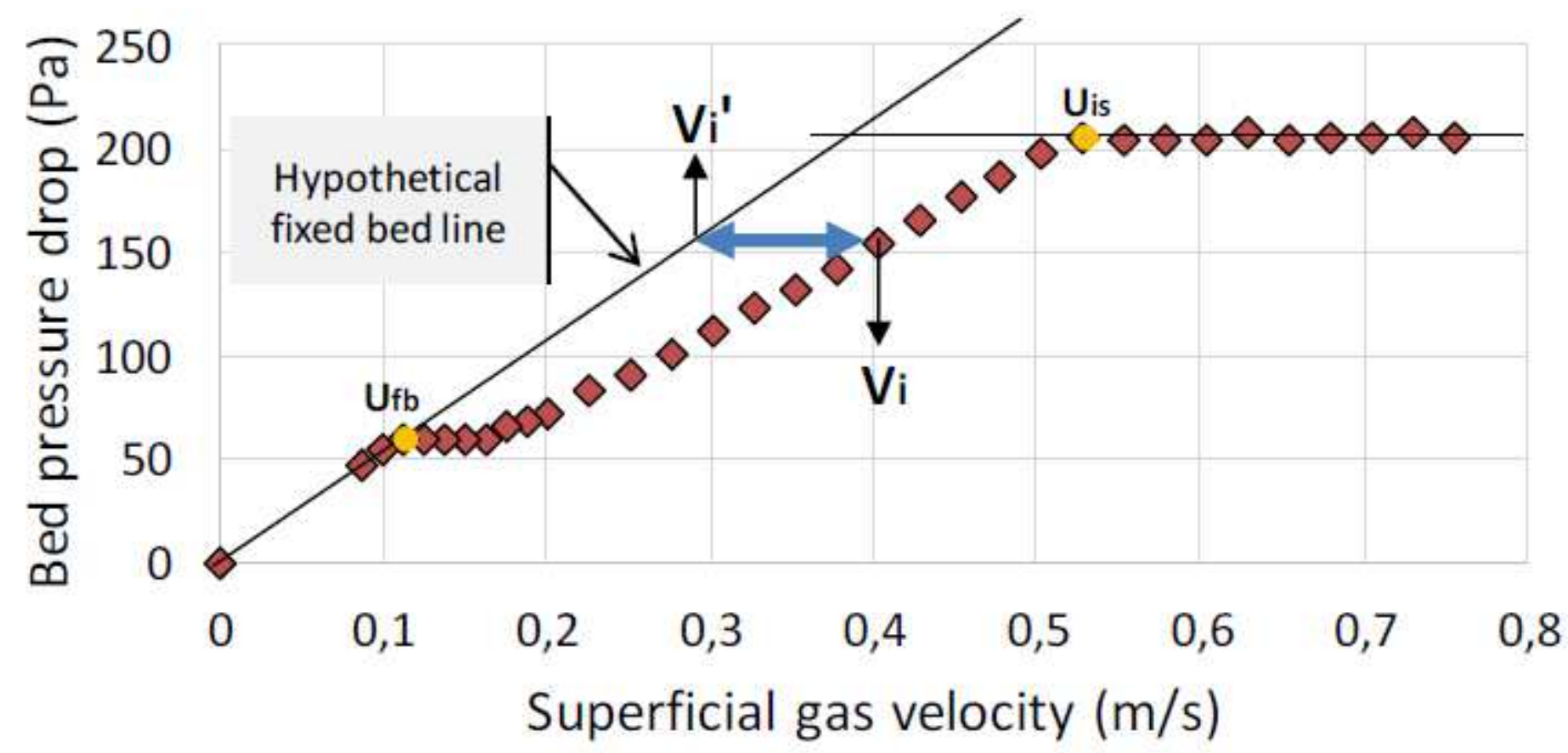

Figure 3

Fluidization with segregation 
(a)

- Increasing velocity - Decreasing velocity

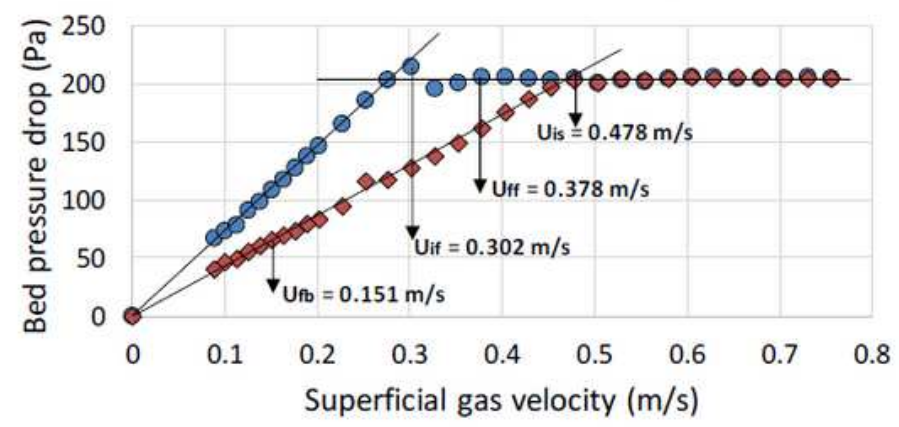

(b)

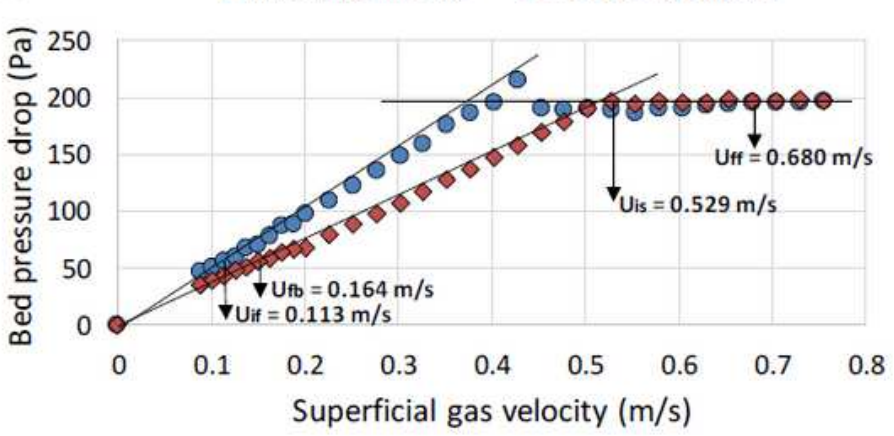

(c)

- Increasing velocity $\diamond$ Decreasing velocity

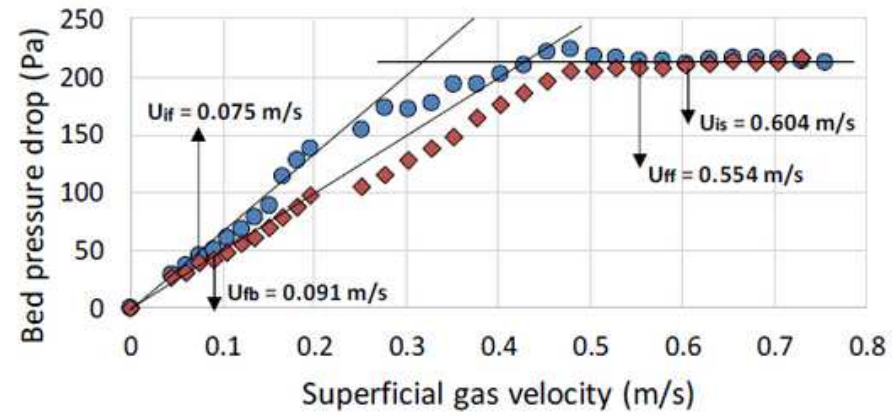

(d) O Increasing velocity $\diamond$ Decreasing velocity

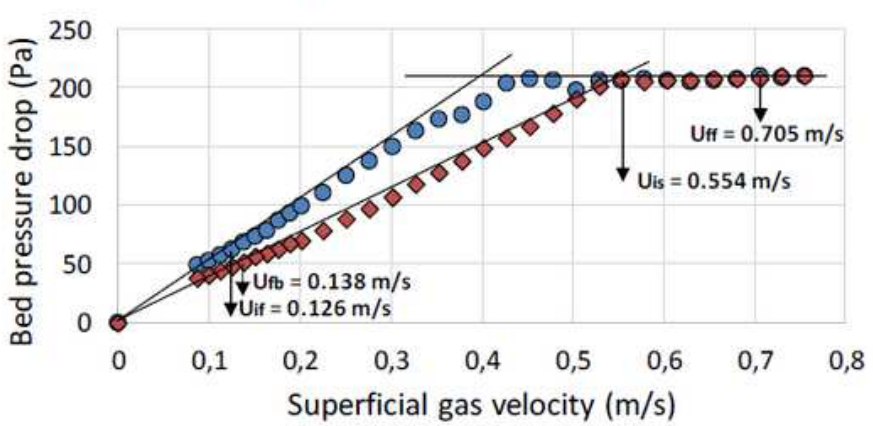

\section{Figure 4}

shows the fluidization curve of four representatives of subgroup $1 \mathrm{~A}$ (tests $1,4,13$, and 16), on $\mathrm{dbio} / \mathrm{dsand}$ e wbio/wbchar $=1$, and particle sizes of 0.66 and $0.95 \mathrm{~mm}$ and fractions masses of 0.05 and 0.08 . 
(a)

O Increasing velocity $\diamond$ Decreasing velocity

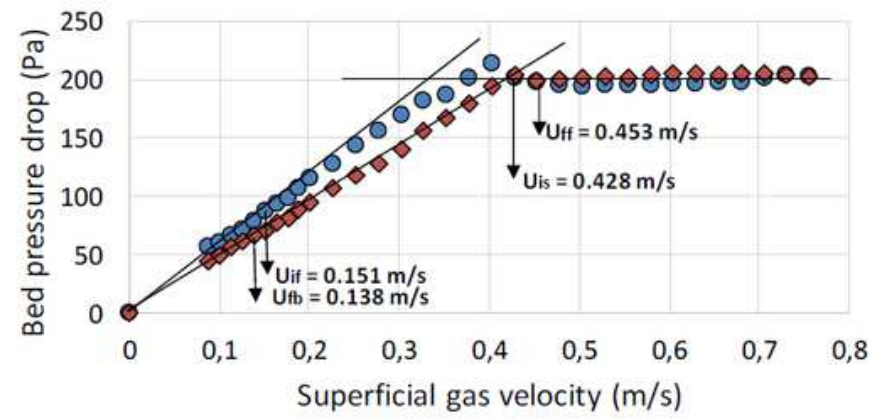

(b) $\quad$ Increasing velocity $\diamond$ Decreasing velocity

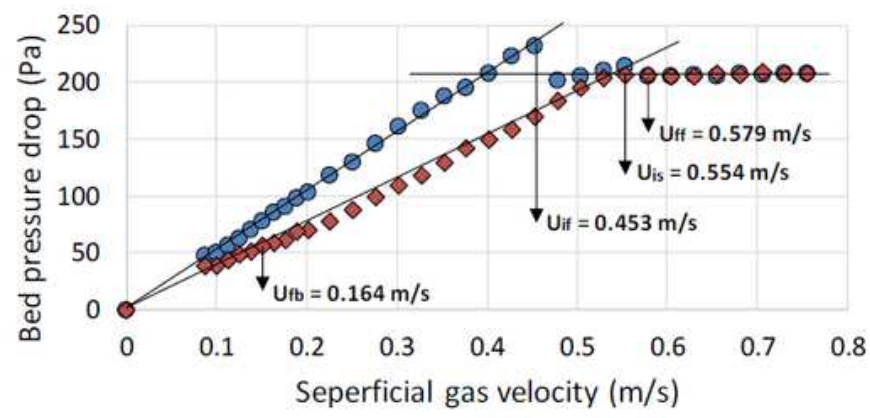

(c) Increasing velocity $\diamond$ Decreasing velocity

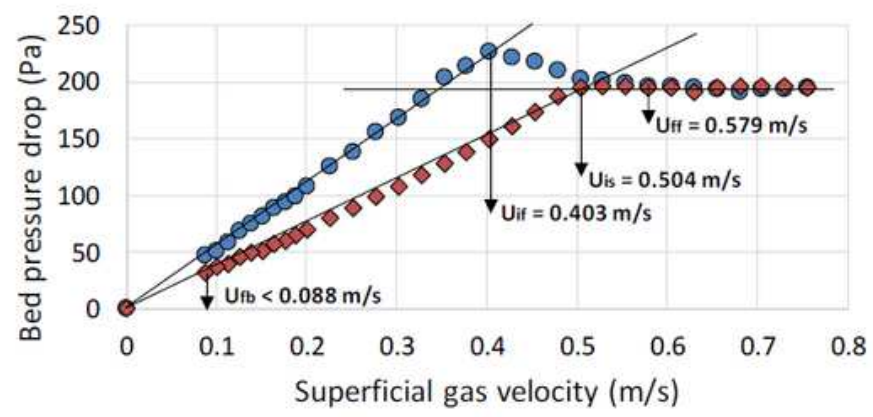

(d) $\quad$ Increasing velocity $\diamond$ Decreasing velocity

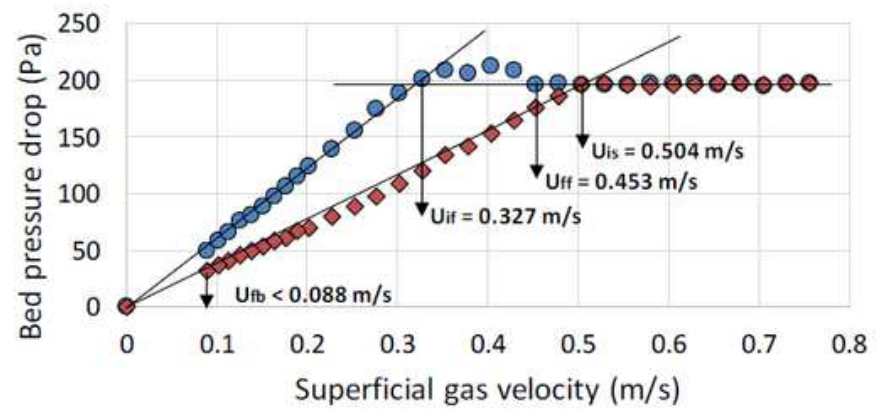

\section{Figure 5}

Pressure drop versus superficial gas velocity for a sand, sisal residue and biochar mixture. Subgroup 1B:

(a) test 9 (dsand $=0.66 \mathrm{~mm}$; dbio $=0.66 \mathrm{~mm}$; wbio $=0.05$; wbchar $=0.08) ;(b)$ test 12 (dsand $=0.95 \mathrm{~mm}$; dbio $=0.95 \mathrm{~mm}$; wbio $=0.05 ;$ wbchar $=0.08) ;($ c $)$ test $23($ dsand $=0.80 \mathrm{~mm} ;$ dbio $=0.80 \mathrm{~mm} ;$ wbio $=$ $0.065 ;$ wbchar $=0.095) ;(d)$ test $26(d s a n d=0.80 \mathrm{~mm} ; \mathrm{dbio}=0.80 \mathrm{~mm}$; wbio $=0.035 ;$ wbchar $=0.065)$ 

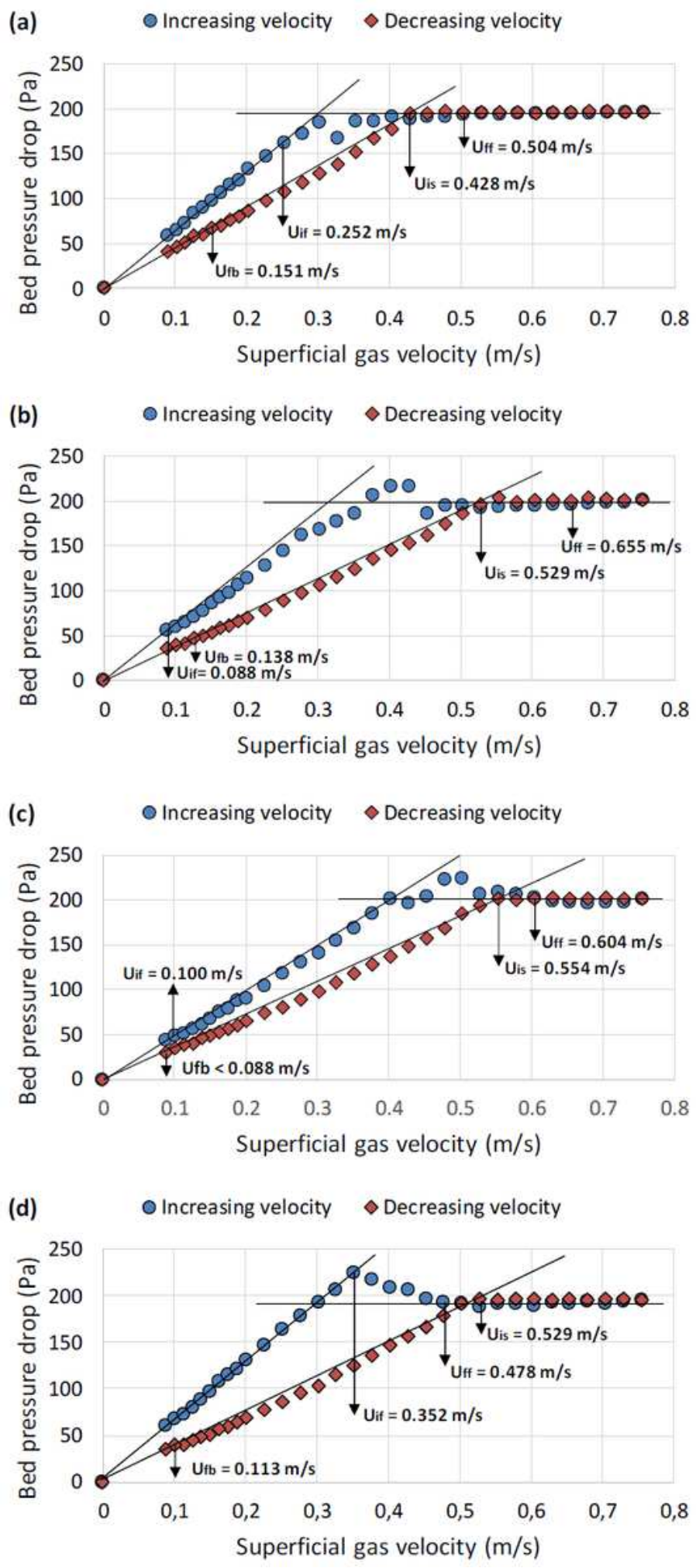

\section{Figure 6}

Pressure drop versus superficial gas velocity for sand, sisal residue and biochar mixture. Subgroup 1C: (a) test 5 (dsand $=0.66 \mathrm{~mm}$; dbio $=0.66 \mathrm{~mm}$; wbio $=0.08$; wbchar $=0.05) ;(b)$ test 8 (dsand $=0.95 \mathrm{~mm}$; dbio $=0.95 \mathrm{~mm}$; wbio $=0.08 ;$ wbchar $=0.05) ;(c)$ test $22($ dsand $=0.80 \mathrm{~mm} ;$ dbio $=0.80 \mathrm{~mm} ;$ wbio $=$ $0.095 ;$ wbchar $=0.065) ;(d)$ test 27 (dsand $=0.80 \mathrm{~mm} ; \mathrm{dbio}=0.80 \mathrm{~mm} ;$ wbio $=0.065 ;$ wbchar $=0.035)$ 


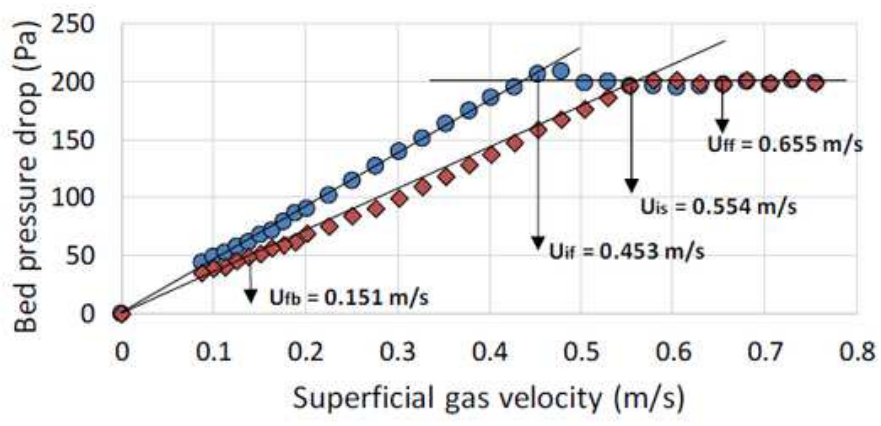

(b)

$$
\text { O Increasing velocity } \diamond \text { Decreasing velocity }
$$

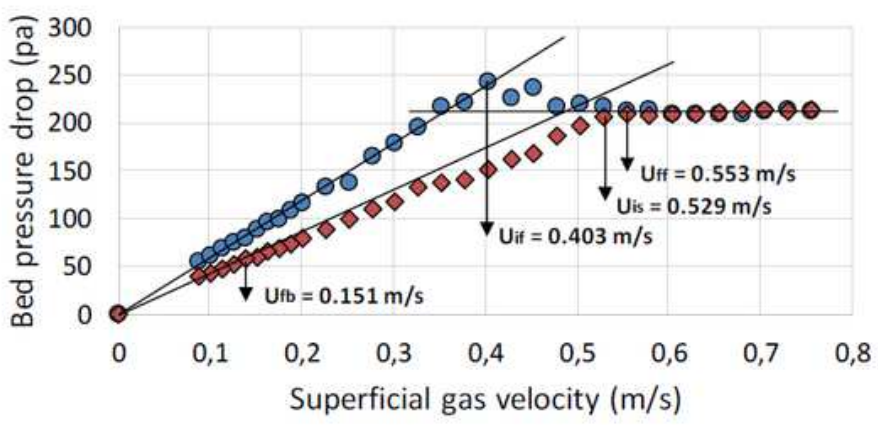

(c) $\quad$ Increasing velocity $\diamond$ Decreasing velocity

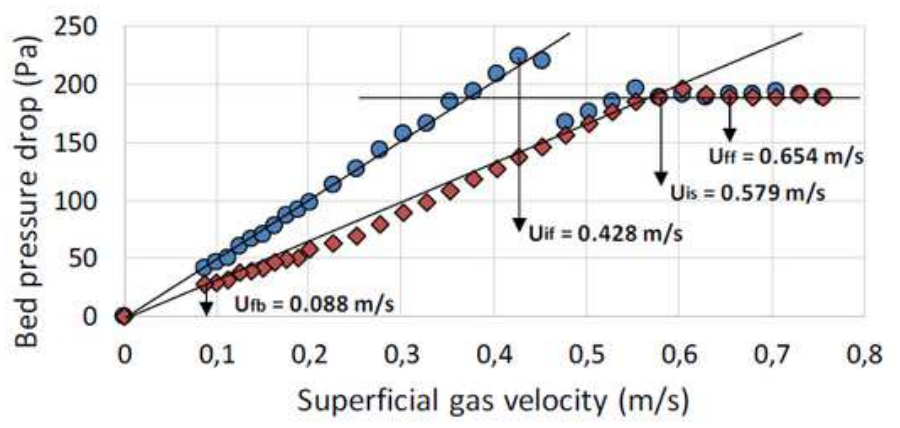

(d) Increasing velocity $\diamond$ Decreasing velocity

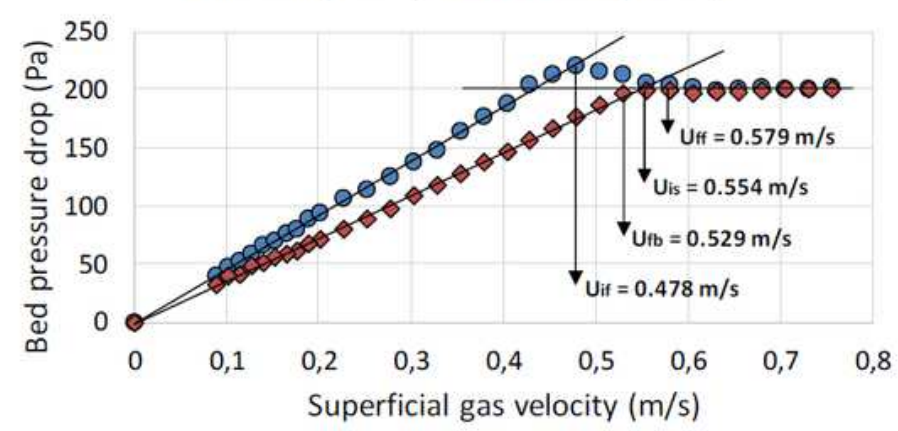

\section{Figure 7}

Pressure drop versus superficial gas velocity for sand, sisal residue and biochar mixture. Subgroup 2A: (a) test 2 (dsand $=0.95 \mathrm{~mm}$; dbio $=0.66 \mathrm{~mm}$; wbio $=0.05$; wbchar $=0.05) ;(b)$ test 14 (dsand $=0.95 \mathrm{~mm}$; dbio $=0.66 \mathrm{~mm}$; wbio $=0.08 ;$ wbchar $=0.08) ;(c)$ test 20 (dsand $=1.10 \mathrm{~mm} ; \mathrm{dbio}=0.80 \mathrm{~mm} ;$ wbio $=0.065$; wbchar $=0.065) ;(d)$ test $25(\mathrm{dsand}=0.85 \mathrm{~mm} ; \mathrm{dbio}=0.51 \mathrm{~mm} ;$ wbio $=0.065 ;$ wbchar $=0.065)$ 
(a)

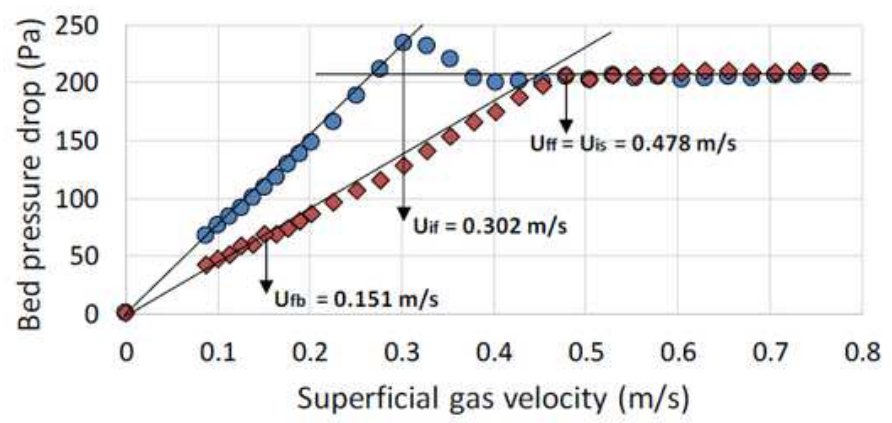

(b) OIncreasing velocity $\diamond$ Decreasing velocity

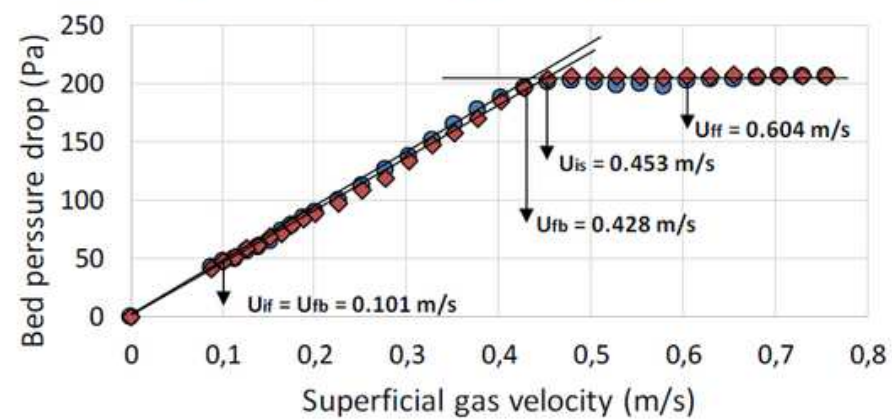

(c) Increasing velocity $\diamond$ Descreasing velocity

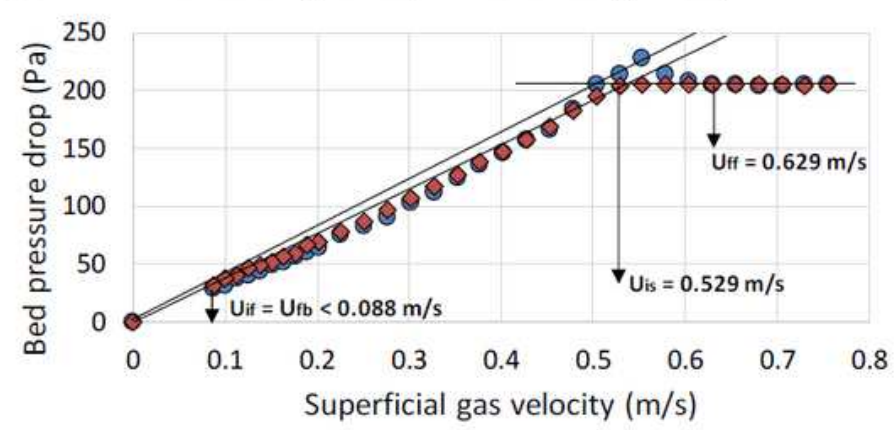

(d) O Increasing velocity $\diamond$ Decreasing velocity

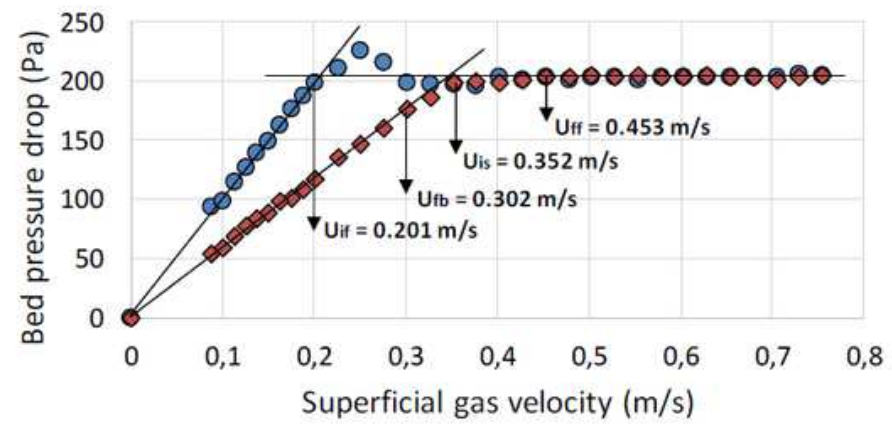

\section{Figure 8}

Pressure drop versus superficial gas velocity for sand, sisal residue and biochar mixture. Subgorup 3A:

(a) test 3 (dsand $=0.66 \mathrm{~mm}$; dbio $=0.95 \mathrm{~mm}$; wbio $=0.05$; wbchar $=0.05) ;(b)$ test 15 (dsand $=0.66 \mathrm{~mm}$; dbio $=0.95 \mathrm{~mm}$; wbio $=0.08 ;$ wbchar $=0.08) ;($ c $)$ test $21(\mathrm{dsand}=0.80 \mathrm{~mm} ; \mathrm{dbio}=1.10 \mathrm{~mm} ;$ wbio $=$ $0.065 ;$ wbchar $=0.065) ;(d)$ test $24(d$ sand $=0.51 \mathrm{~mm} ; \mathrm{dbio}=0.80 \mathrm{~mm} ;$ wbio $=0.065 ;$ wbchar $=0.065)$ 
(a)

- Increasing velocity $\diamond$ Decreasing velocity

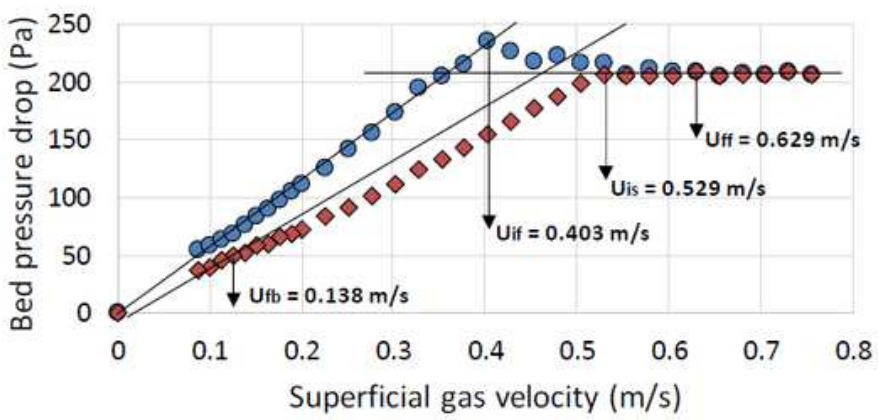

(b) O Increasing velocity $\diamond$ Decreasing velocity

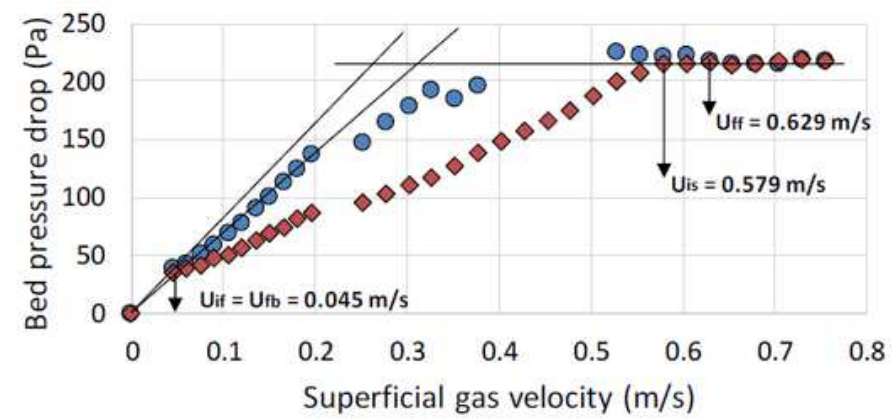

(c) Increasing velocity $\diamond$ Decreasing velocity

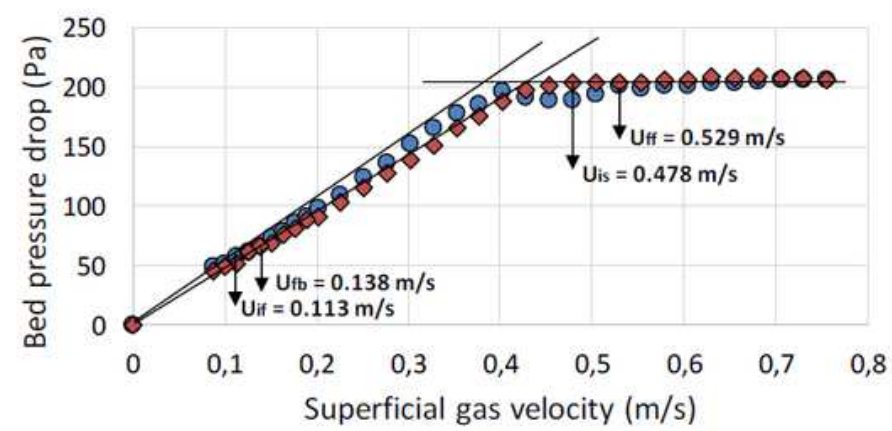

(d) Increasing velocity $\diamond$ Decreasing velocity

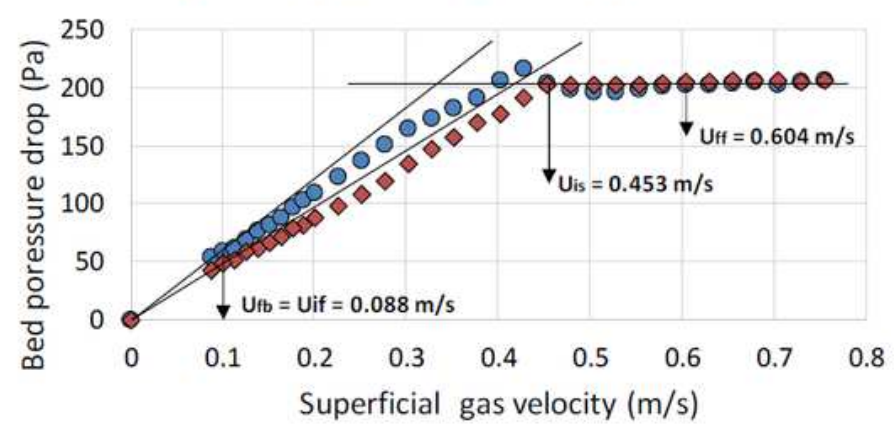

\section{Figure 9}

Pressure drop versus superficial gas velocity for sand, sisal residue and biochar mixture. Subgroup 2B:

(a) test 10 (dsand $=0.95 \mathrm{~mm}$; dbio $=0.66 \mathrm{~mm}$; wbio $=0.05$; wbchar $=0.08$ ); Subgroup 2C: (b) test 6 (dsand $=0.95 \mathrm{~mm}$; dbio $=0.66 \mathrm{~mm}$; wbio $=0.08$; wbchar $=0.05)$; Subgroup 3B: (c) test 11 (dsand $=0.66$ $\mathrm{mm} ; \mathrm{dbio}=0.95 \mathrm{~mm}$; wbio $=0.05 ;$ wbchar $=0.08)$; Subgroup 3C: $(\mathrm{d})$ test 7 (dsand $=0.66 \mathrm{~mm}$; dbio $=0.95$ $\mathrm{mm} ;$ wbio $=0.08 ;$ wbchar $=0.05$ ) 

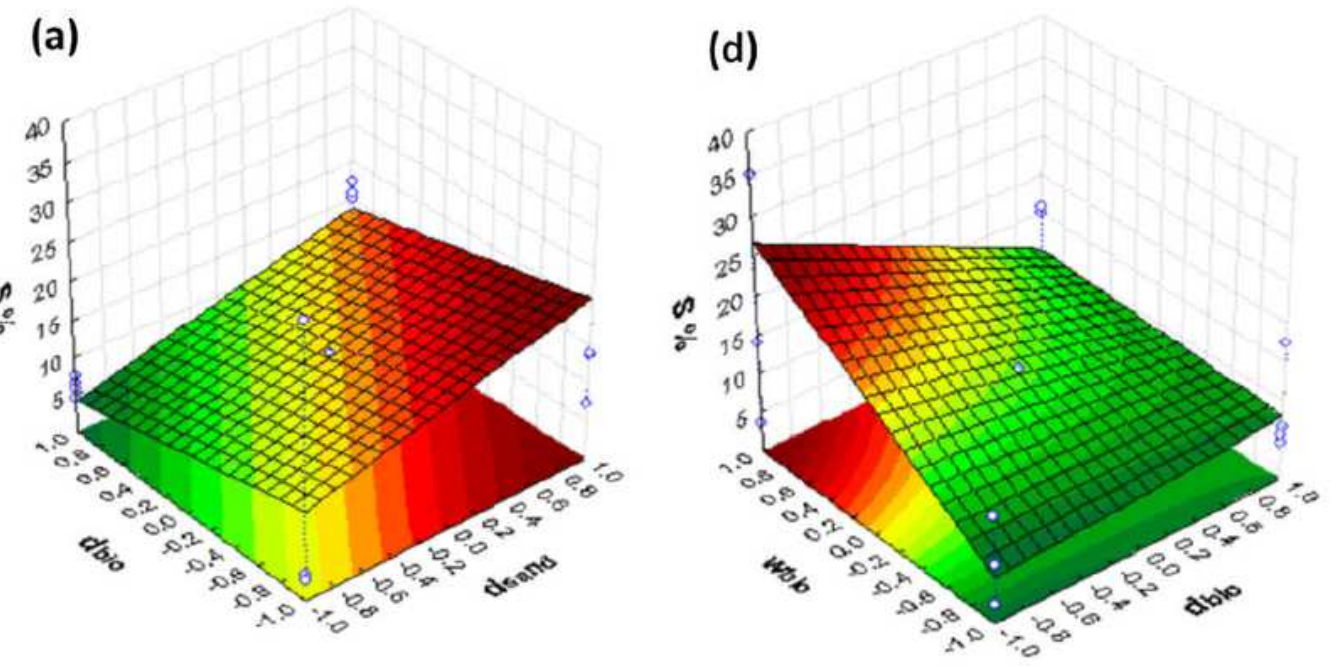

(b)
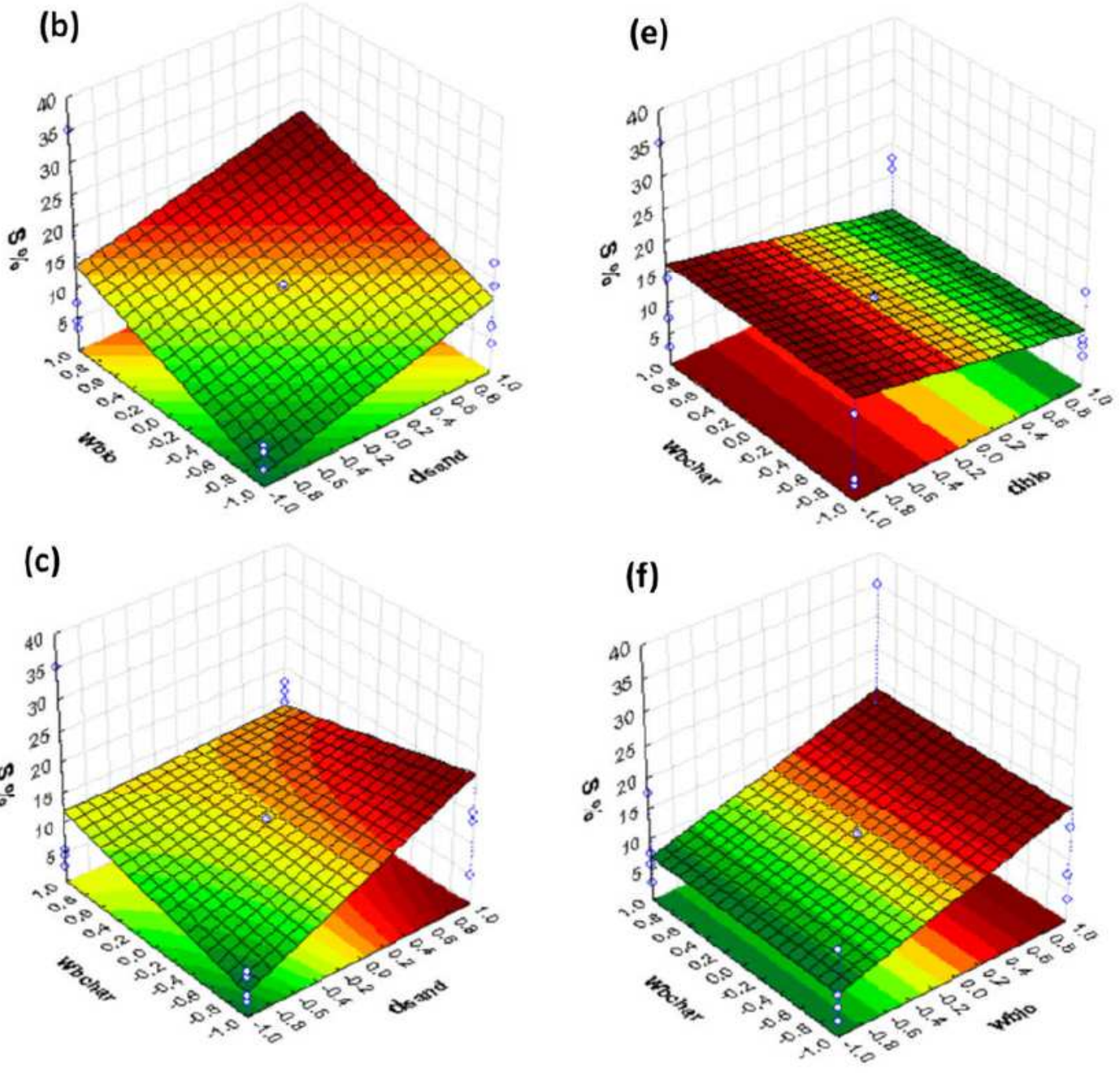

\section{Figure 10}

Response surface representing the combined effects on the segregation percentage between sand particle size, sisal residue particle size, sand/sisal residue mass fraction, and sand/biochar mass fraction 

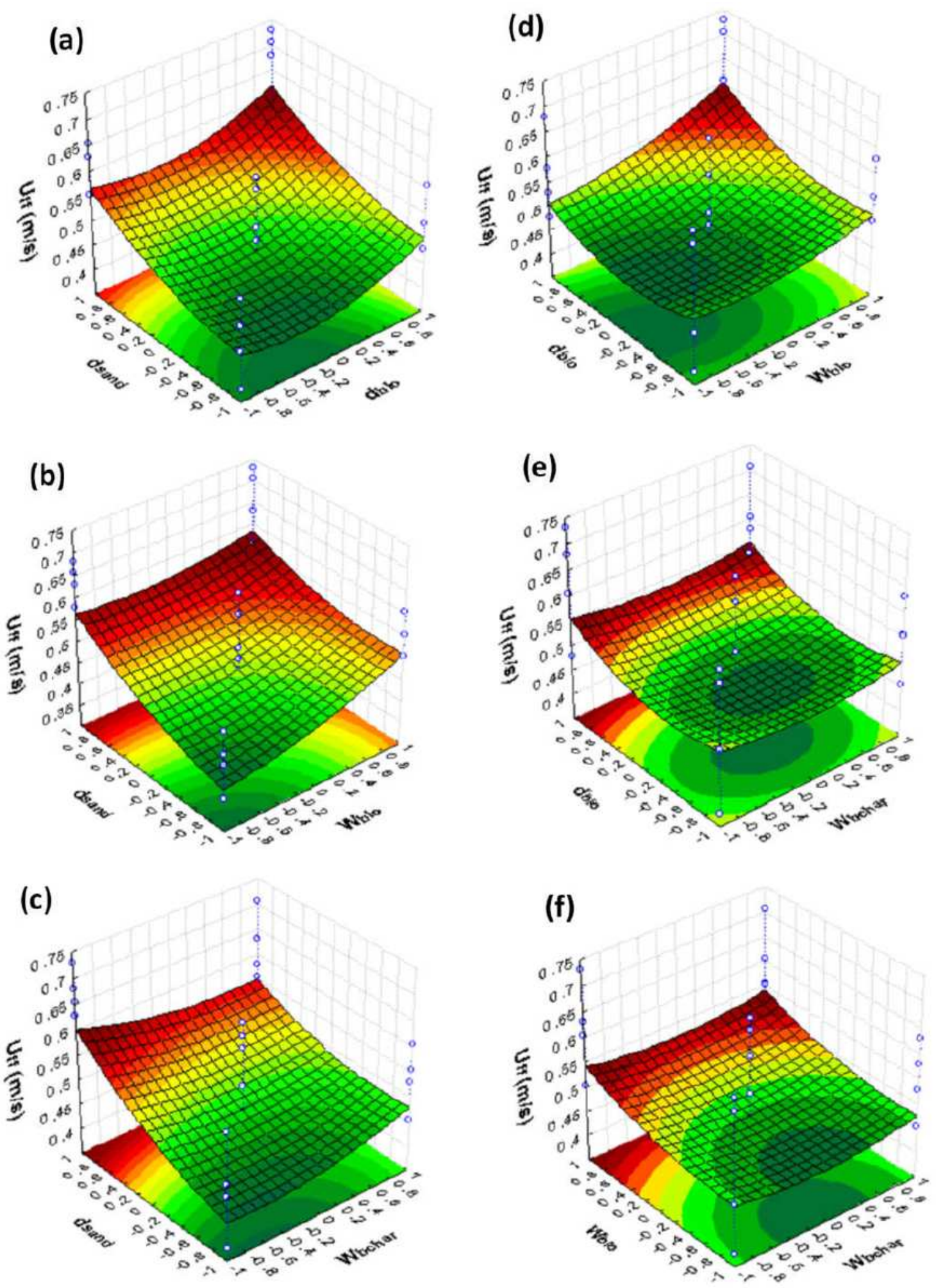

\section{Figure 11}

shows the three-dimensional surfaces that were plotted to study the interactions between six pairs of variables (dsand and dbio; dsand and wbio; dsand and wbchar; dbio and wbio, dbio and wbchar, wbio and wbchar). 


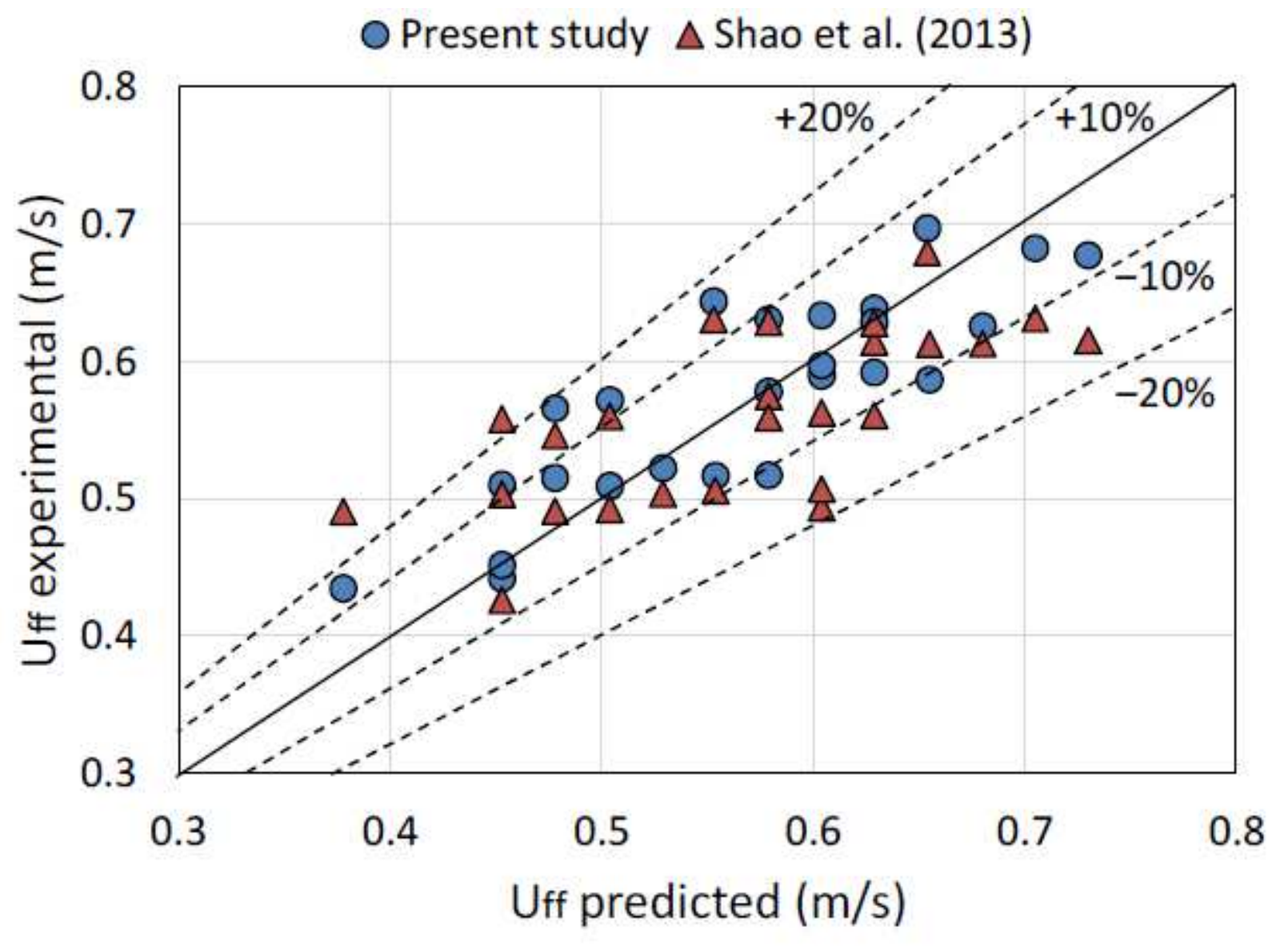

Figure 12

Predicted versus experimental final fluidization velocity for the tertiary mixture of sand, sisal residue, and biochar

\section{Supplementary Files}

This is a list of supplementary files associated with this preprint. Click to download.

- Table.pdf

- Supplementarymaterial.pdf 